\title{
Use of Cutting-Edge Horizontal and Underbalanced Drilling Technologies and Subsurface Seismic Techniques to Explore, Drill and Produce Reservoired Oil and Gas from the Fractured Monterey Below 10,000 ft in the Santa Maria Basin of California \\ Technical Progress Report
}

September 30, 2003 to September 29, 2004

by

George Witter (Temblor Petroleum Company)

Robert Knoll (Maurer Technology Inc.)

William Rehm (Maurer Technology Inc.)

Thomas Williams (Maurer Technology Inc.)

February 2005

DE-FC26-03NT15426

Temblor Petroleum Company, LLC

2000 Oak Street, Suite 200

Bakersfield, California 93301

Maurer Technology Inc.

13135 South Dairy Ashford, Suite 800

Sugar Land, Texas 77478 


\section{Disclaimer}

This report was prepared as an account of work sponsored by an agency of the United States Government. Neither the United States Government nor any agency thereof, nor any of their employees, makes any warranty, express or implied, or assumes any legal liability or responsibility for the accuracy, completeness, or usefulness of any information, apparatus, product, or process disclosed, or represents that its use would not infringe privately owned rights. Reference herein to any specific commercial product, process, or service by trade name, trademark, manufacturer, or otherwise does not necessarily constitute or imply its endorsement, recommendation, or favoring by the United States Government or any agency thereof. The views and opinions of authors expressed herein do not necessarily state or reflect those of the United States Government or any agency thereof. 


\section{Abstract}

This project was undertaken to demonstrate that oil and gas can be drilled and produced safely and economically from a fractured Monterey reservoir in the Santa Maria Basin of California by employing horizontal wellbores and underbalanced drilling technologies. Two vertical wells were previously drilled in this area by Temblor Petroleum with heavy mud and conventional completions; neither was commercially productive. A new well was drilled by the project team in 2004 with the objective of accessing an extended length of oil-bearing, high-resistivity Monterey shale via a horizontal wellbore, while implementing managed-pressure drilling (MPD) techniques to avoid formation damage.

Initial project meetings were conducted in October 2003. The team confirmed that the demonstration well would be completed open-hole to minimize productivity impairment. Following an overview of the geologic setting and local field experience, critical aspects of the application were identified.

At the pre-spud meeting in January 2004, the final well design was confirmed and the well programming/service company requirements assigned. Various design elements were reduced in scope due to significant budgetary constraints. Major alterations to the original plan included: 1) a VSP seismic survey was delayed to a later phase; 2) a new (larger) surface hole would be drilled rather than re-enter an existing well; 3) a 7-in. liner would be placed into the top of the Monterey target as quickly as possible to avoid problems with hole stability; 4) evaluation activities were reduced in scope; 5) geosteering observations for fracture access would be deduced from penetration rate, cuttings description and hydrocarbon in-flow; and 6) rather than use nitrogen, a novel air-injection MPD system was to be implemented.

Drilling operations, delayed from the original schedule by capital constraints and lack of rig availability, were conducted from September 12 to November 11, 2004. The vertical and upper curved sections were drilled and lined through the problematic shale member without major stability problems. The top of the targeted Monterey was thought to be seen at the expected TVD of $10,000 \mathrm{ft}$ where the 7 -in. liner was set at a $60^{\circ}$ hole angle. Significant oil and gas shows suggested the fractured interval anticipated at the heel location had been penetrated.

A total of $2572 \mathrm{ft}$ of $61 / 8$-in. near-horizontal interval was placed in the shale section, extending planned well length by approximately $470 \mathrm{ft}$. Very little hydrocarbon in-flow was observed from fractures along the productive interval. This may be a result of the well trajectory falling underneath the Monterey fractured zone. Hydrocarbon observations, cuttings analysis and gamma-ray response indicated additional fractured intervals were accessed along the last \pm 900 $\mathrm{ft}$ of well length. The well was completed with a $27 / 8$-in. tubing string set in a production packer in preparation for flow and swab tests to be conducted later by a service rig.

The planned well time was estimated as 39 days and overall cost as $\$ 2.4$ million. The actual results are 66 days at a total cost of $\$ 3.4$ million. Well productivity responses during subsequent flow and swabbing tests were negative. The well failed to inflow and only minor amounts (a few barrels) of light oil were recovered. The lack of production may suggest that actual sustainable reservoir pressure is far less than anticipated.

Temblor is currently investigating the costs and operational viability of re-entering the well and conducting an FMI (fracture detection) log and/or an acid stimulation. No final decision or detailed plans have been made regarding these potential interventions at this time. 


\section{Table of Contents}

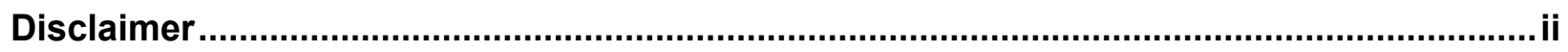

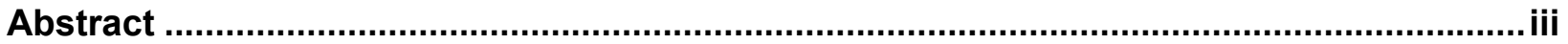

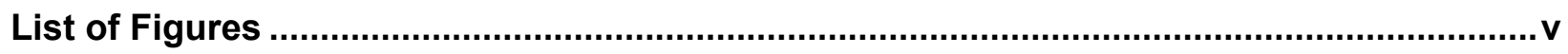

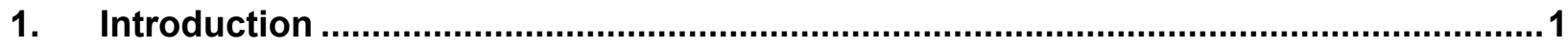

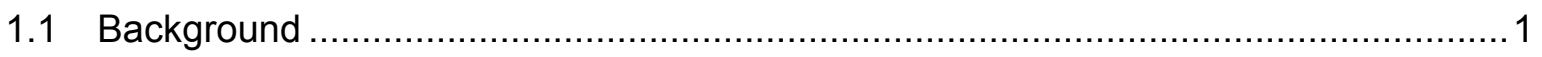

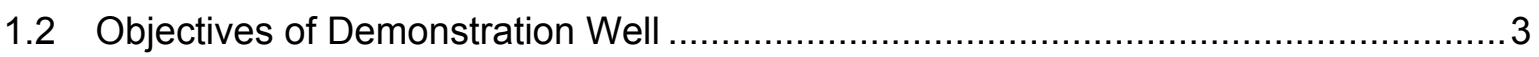

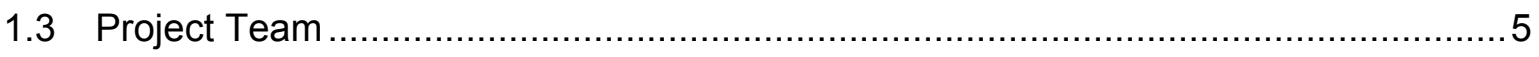

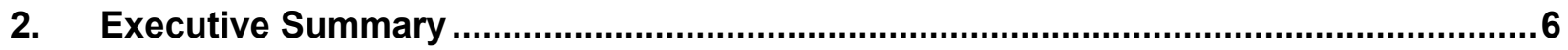

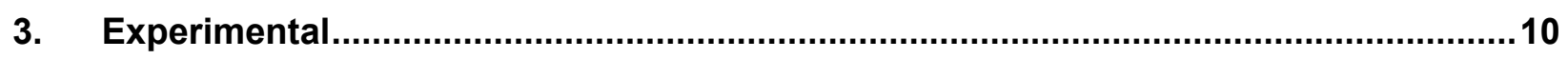

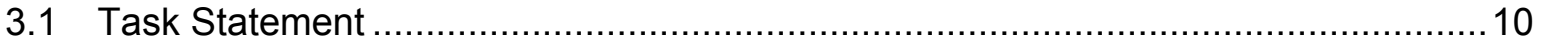

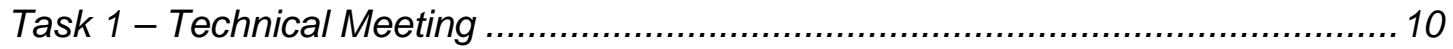

Task 2 - Redrill and Complete the Primary Project Well ......................................10

Task 3 - Produce and Test Primary Project Well..................................................11

Task 4 - Conduct and Analyze VSP Survey ....................................................11

Task 5 - Drill, Test and Produce Additional Horizontal Wells from Same Location .. 11

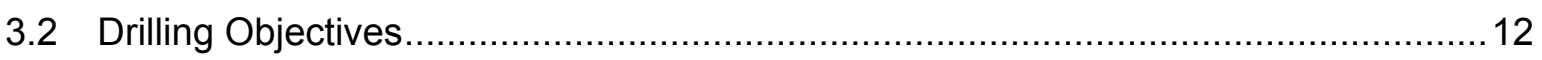

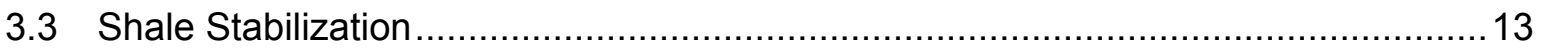

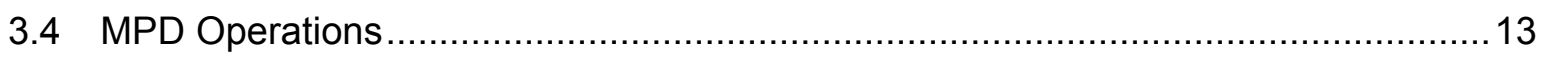

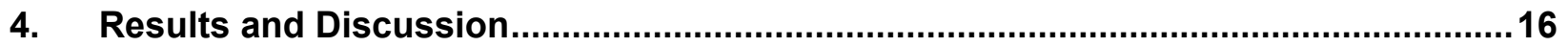

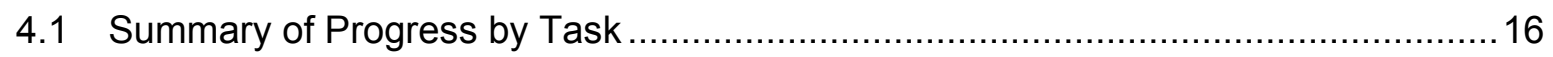

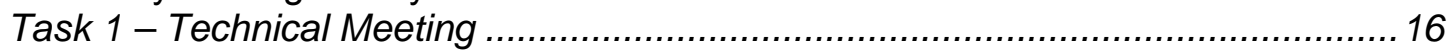

Task 2 - Redrill and Complete the Primary Project Well .....................................16

4.2 Shale Stabilization and Disposal ....................................................................

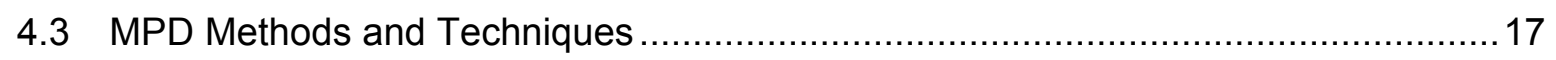

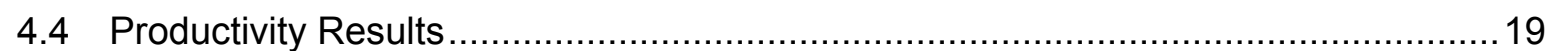

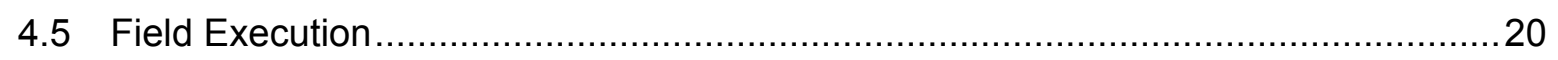

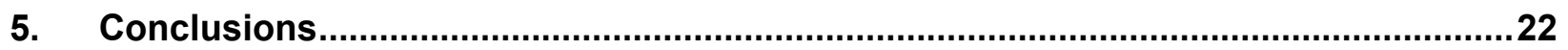

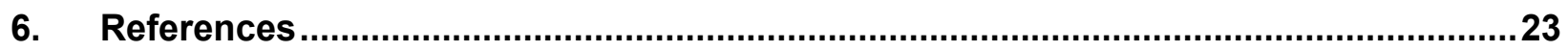

Appendix A: Notes from Project Team Meetings in Bakersfield

Appendix B: Drilling Program for Castillo, Ross and Howe 2-19

Appendix C: Daily Drilling Diary and Operational Comments

Appendix D: Synopsis of Petroleum Indicators in the Monterey Formation 


\section{List of Figures}

Figure 1. Location of Project Well in Los Alamos Prospect ............................................... 2

Figure 2. Outcrop of Fractures Near Well Location..................................................... 2

Figure 3. Surface and Bottomhole Location of Original Well ............................................ 3

Figure 4. Application Objective ................................................................................ 4

Figure 5. Plan (blue) and Actual (red) Well Paths ........................................................ 8

Figure 6. Plan and Actual Time/Depth Curves ................................................................ 9

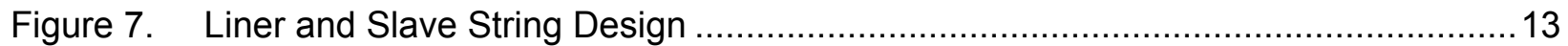

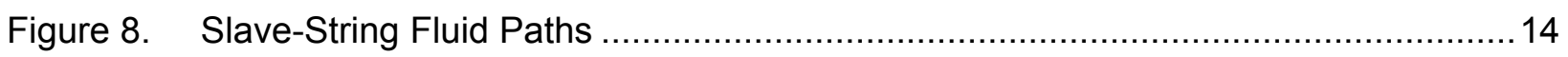

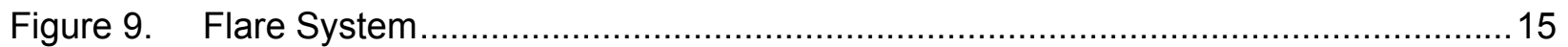

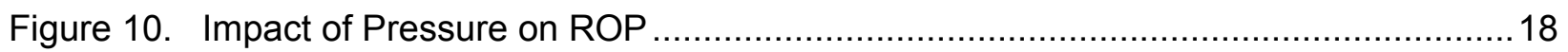




\section{Introduction}

\subsection{Background}

This project was undertaken to demonstrate that oil and gas can be explored, drilled and produced safely and economically from a fractured Monterey reservoir in the Santa Maria Basin of California by employing cutting-edge horizontal and underbalanced drilling methods, and subsurface seismic exploratory techniques. Two wells were previously drilled vertically in this area by Temblor Petroleum Company LLC with heavy mud and completed conventionally by running and cementing casing, perforating and acidizing. Neither well was commercially productive even though very strong shows of oil and gas were obtained while drilling, and free oil and gas were recovered from both wells during and after completion, with no indication of water. Seismic and well data indicate a structural trap of some 1500 acres and an oil column of at least $700 \mathrm{ft}$, providing a potential accumulation of 30 to 50 million barrels of 31 gravity oil, and 30 to 50 BCF of gas.

To demonstrate the implementation of cutting-edge drilling techniques in this setting, a new well (the Castillo, Ross and Howe 2-19) was drilled by Temblor on the location: SEC 19 T8N R32W, Santa Barbara County, California, in the fall of 2004 (Figure 1). The project's objective was to access a minimum of $2100 \mathrm{ft}$ of oil-bearing, high-resistivity Monterey shale with a horizontal wellbore. The Monterey Formation is a fractured/micro-fractured Miocene reservoir that has produced most of the oil and gas in the Santa Maria Basin onshore region of south central California. The target reservoir is at a depth exceeding 10,000 ft true vertical depth (TVD). All historical and commercial onshore production from the high-resistivity section of the Monterey has come from fields at much shallower depths $-5000 \mathrm{ft}$ TVD or less.

An initial discovery well was drilled by Oxy in 1986. The target was defined by seismic as a down-thrown fault block or graben. This vertical well penetrated and logged approximately 700 $\mathrm{ft}$ of a light oil column $\left(31^{\circ} \mathrm{API}\right)$ at 10,500 ft TVD in the high-resistivity Monterey. Although a flow test delivered an initial rate of 48 BOPD, flow declined within hours. The well would not sustain commercial production and was abandoned. Temblor drilled a second delineation well in 1999. This well was drilled from a new surface location approximately 0.5 mile southeast of the discovery well surface location.

This second well was directionally drilled ( $30^{\circ}$ inclination) so that its bottom-hole location was only $400 \mathrm{ft}$ laterally displaced from the discovery well within the Monterey target interval. The second well also logged approximately $700 \mathrm{ft}$ of light oil column with no evidence of bottom water or top gas. Although the well flowed for a short period (10 BOPD for 1.5 hours), it would not sustain commercial flow rates after an acid stimulation treatment, and was suspended. 


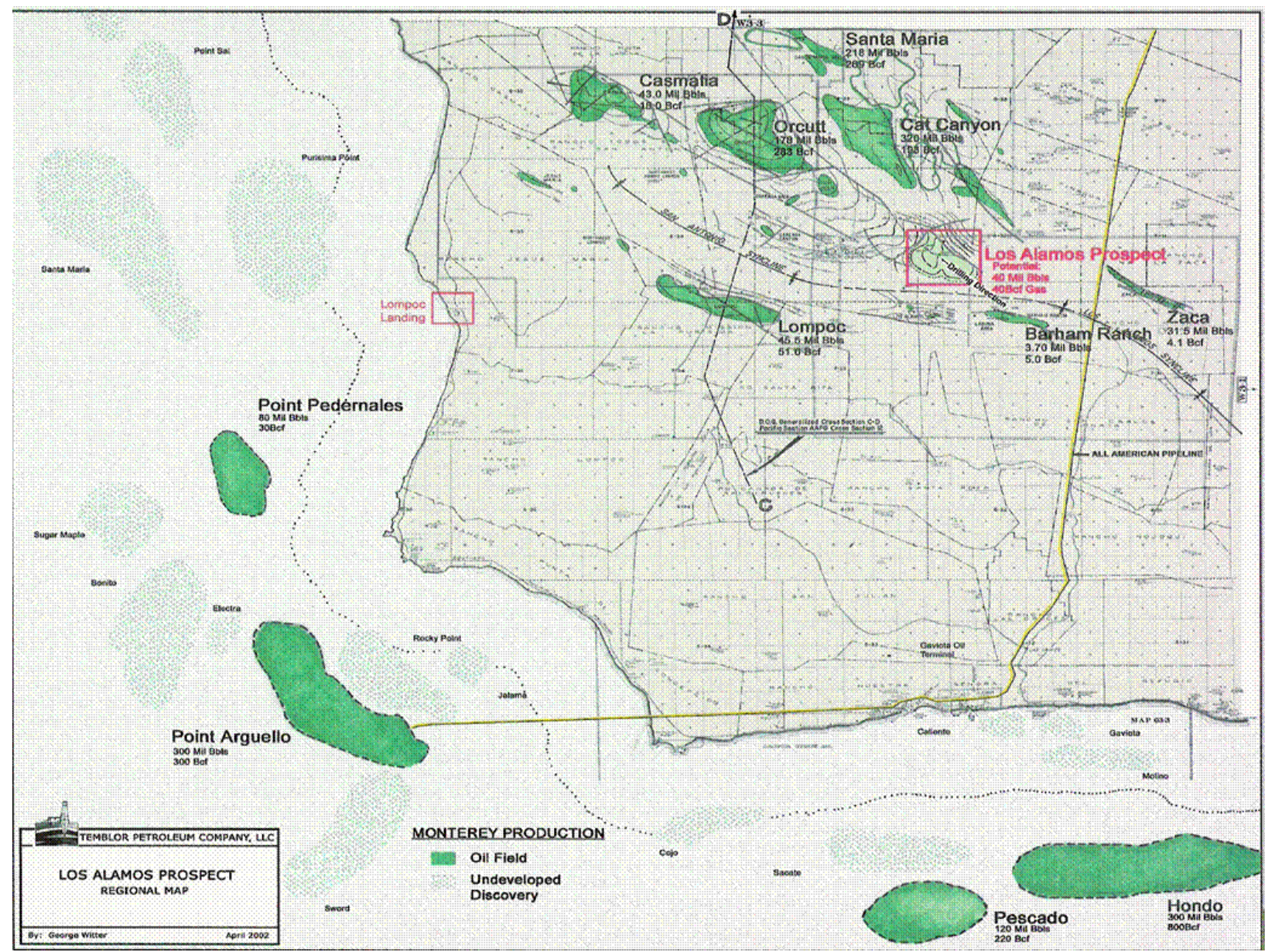

Figure 1. Location of Project Well in Los Alamos Prospect

Both original wells were vertical to sub-vertical, and it appears only the first "discovery" well was near to (or accessed) a set of natural vertical fractures. Fractures are clearly seen in nearby outcrops (Figure 2) and are expected to trend NE-SW within the Monterey due to the local stress state.

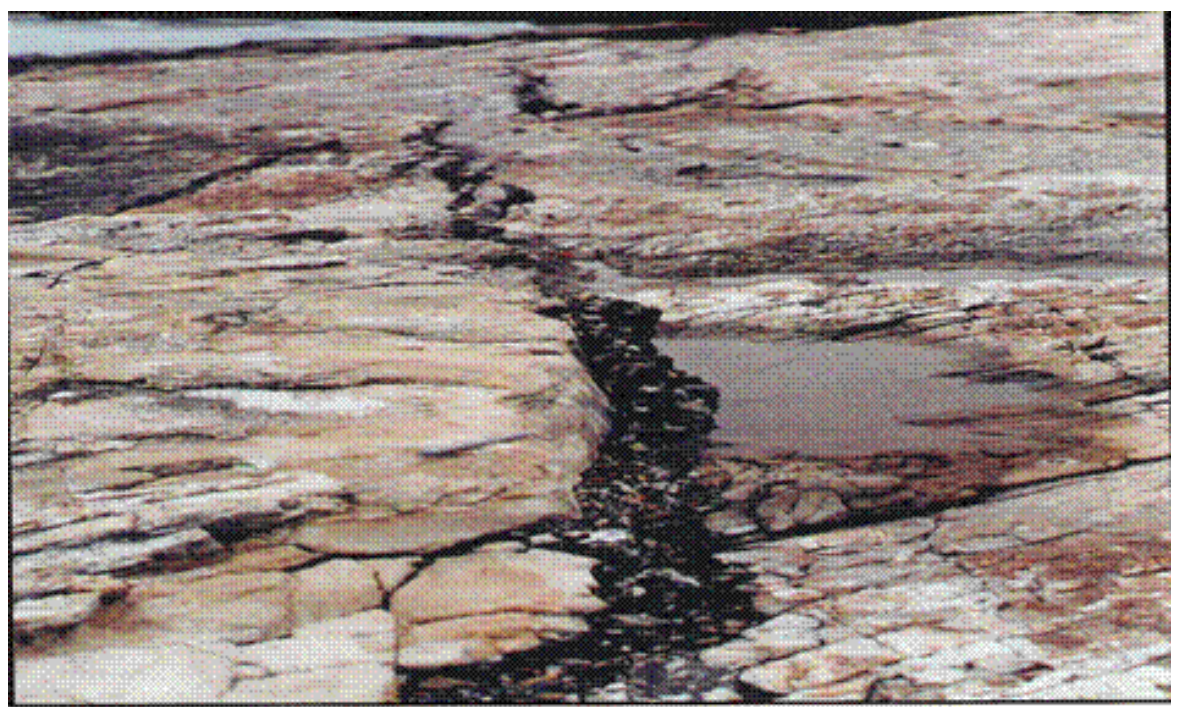

Figure 2. Outcrop of Fractures near Drilling Location 
The target is in a seismically mapped structure covering some 1500 acres (Figure 3 ). The target is estimated to contain between 36 to 54 million barrels of light oil reserves with 36 to 54 BCF of gas. Successful exploitation of this structure by horizontally accessing vertical fractures in a non-damaging mode is expected to deliver production of \pm 600 BOPD, and would promote significant interest in similar deep Monterey structures thought to be prevalent in the area.

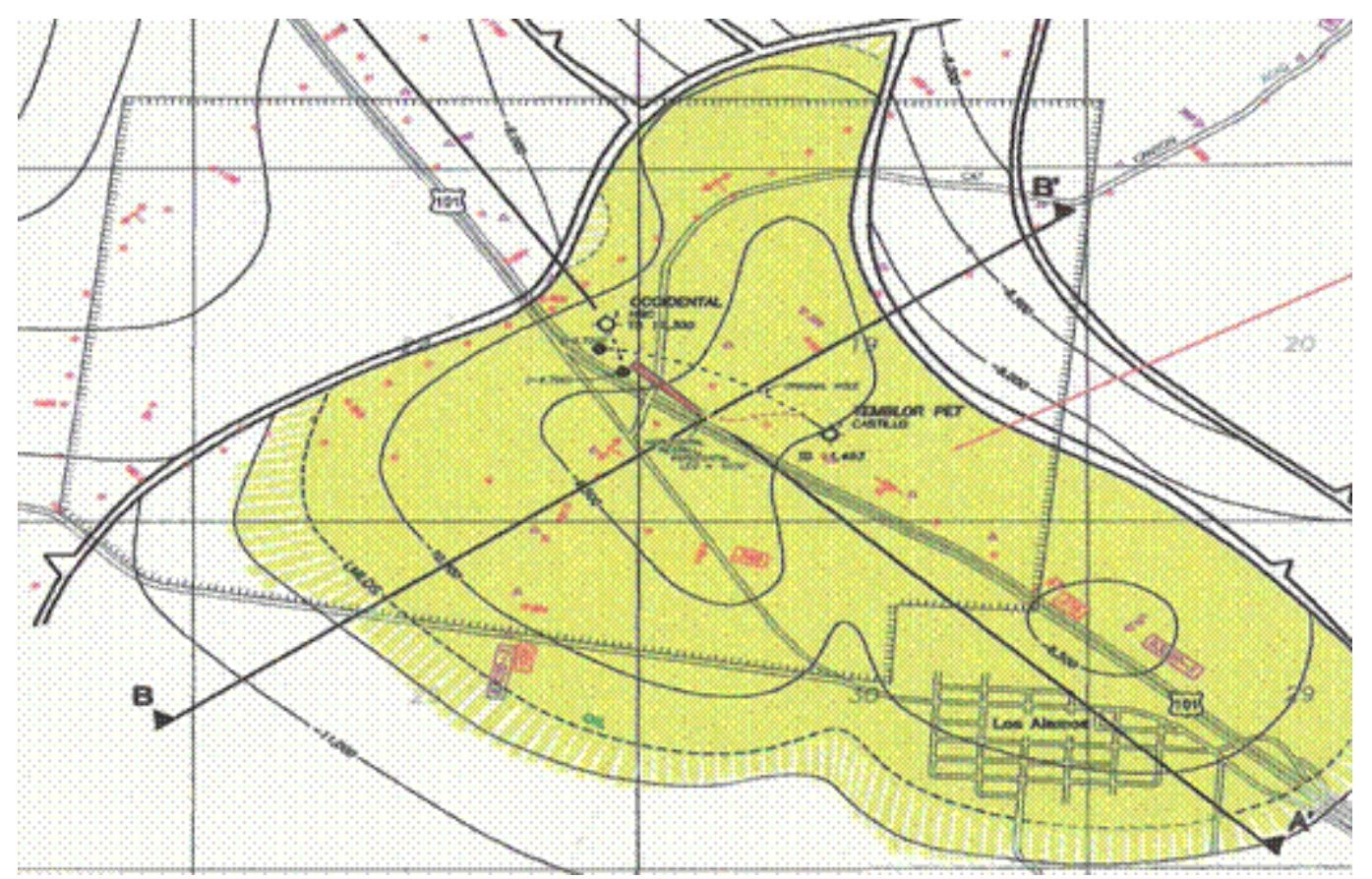

Figure 3. Surface and Bottomhole Location of Original Well

General geology, drilled cuttings analysis, logs and pressure test data from both original Temblor wells suggested the existence of oil-filled vertical fractures within the shale. Pressure build-up and flow test results conducted on the delineation well suggested a dual-porosity system, with extremely tight matrix permeability in the shale. The degree of micro-fracturing in the shale matrix is thought to be a key unknown. All pressure build-up interpretations were qualitative at best due to the very tight nature of the shale matrix (less than 0.01 millidarcy), the unknown proximity to fractures/micro-fractures, and the potential for skin damage. Based on test interpretations and observed suspended well shut-in surface pressures, reservoir pressure was expected to be in the range of $4600-5200$ psi.

High mud weights were required to hold back a massive ( $\pm 4000 \mathrm{ft}$ thick) and problematic "Sisquoc" shale member above the Monterey in both original wells. Extensive stability problems in this interval had led to many costs overruns in both previous wells, and were seen as a major well construction challenge in the demonstration well. High mud weights were also seen as very unattractive in any productive interval due to productivity damage (skin) concerns.

\subsection{Objectives of Demonstration Well}

To mitigate the concerns highlighted in the two earlier wells, the proposed demonstration well would be drilled using novel managed-pressure drilling (MPD) methods, including the use of a drilling deployment valve (DDV) to allow normal tripping operations while maintaining the 
bottom-hole pressure target of approximately 4400-4600 psi. The basic objective of this new effort was to implement advanced MPD techniques to acquire economic production rates from a fractured Monterey reservoir by accessing multiple fracture sets in a non-damaging mode. The application objective is shown in Figure 4.

At $100^{\prime}$ Fracture Spacing:

Temblors 0 intercepts

$\mathrm{OXY}: \quad 1$ intercept $-48 \mathrm{BOPD}$

Horizontal Well 10 to 18 intercepts - 480 BOPD to 864 BOPD

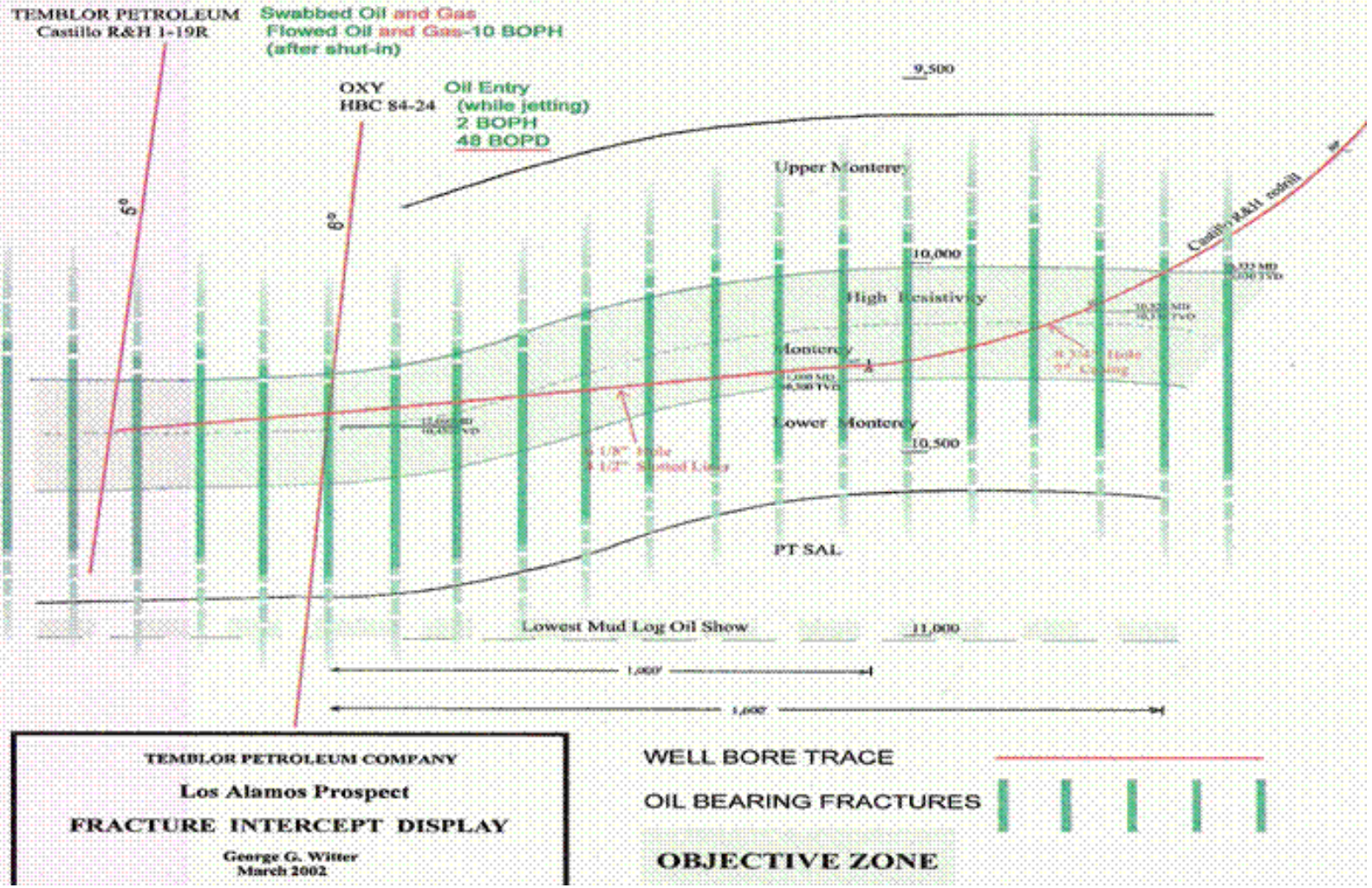

Figure 4. Application Objective

The original concept evaluated was to reenter the suspended delineation well to drill the highresistivity Monterey in a near-horizontal attitude. However, wellbore stability and well profile concerns in the curved section and MPD equipment requirements made this option unviable. To give the well the best operational setting, a new well was planned from the delineation well's surface location. This allowed:

1. A spatial arrangement whereby the heel of the new well could access a potential fractured interval (identified by seismic interpretation) directly below the surface location. The remainder of the $2100 \mathrm{ft}$ of near-horizontal interval $\left(80^{\circ}\right.$ angle) would follow a downstructure direction (azimuth $300^{\circ}$ ). Seismic interpretation and well control suggested a structural drop of approximately $300 \mathrm{ft}$ from the demonstration well's heel target to the toe target. The toe of the well would terminate within close proximity $( \pm 100 \mathrm{ft}$ laterally displaced) from the discovery well's bottom-hole location.

2. The use of the existing location to construct a new, straight and larger main vertical section through the majority of the problematic shale member. This new intermediate 
section and upper curve could be drilled with high mud weights and cased with 7 -in. liner into the mid-section of the Monterey at an $80^{\circ}$ angle.

3. A new high-pressure-rated 103/4/7-in. surface liner design allowing for placement of a down-hole deployment valve at the top of the liner in a retrievable 7 -in. slave string.

4. The slave string allowed simple air injection (air-lift) at $3200 \mathrm{ft}$ TVD. This novel approach provided capability for MPD without the requirement of special motors/MWD/LWD equipment or practices necessary when conducting MPD with conventional aerated fluids. The use of air also provided significant cost savings versus nitrogen.

\subsection{Project Team}

A multi-disciplined project team was assembled comprising several consultants, consulting groups or companies, each experts in their own field, in a coordinated effort to achieve the project objectives. Total project coordination and supervision is being provided by Temblor. Imke Consulting provides basic well planning, well-site rig supervision, contracting and coordination for well-site services including rig selection. Imke was primarily responsible for the plug back and early drilling phases of the program, running casing. and final completion. Maurer Technology is primarily responsible for coordination and planning of the horizontal and underbalanced drilling phases of the project. Weatherford International, Inc. provided underbalanced drilling expertise, equipment and personnel. Scientific Drilling provided state-ofthe-art directional drilling technology, equipment and personnel for all phases of the primary project well. Paulsson Geophysical Services was to be enlisted to provide technology and equipment for the vertical seismic profile (VSP) survey. 


\section{Executive Summary}

The basic objective of this effort was to implement advanced managed-pressure drilling (MPD) techniques to acquire economic production rates from a fractured Monterey reservoir by accessing multiple fracture sets in a non-damaging mode. The first project meetings were held in Bakersfield in October 2003. Basic objectives of the project were confirmed. The demonstration well would be completed open-hole to minimize productivity impairment of the fractured target zone, and provide the most intervention options in the future should the well not respond as expected. Following an overview of the geologic setting and local field experience, three critical aspects of the application were identified:

1. Problematic Sisquoc shale and related hole problems must be mitigated in the main vertical and upper curve section.

2. Significant geologic and structure uncertainty exists. Optimum placement of the lower curve/heel of the well into the high-resistivity Monterey target was seen as critical to success. This would require definition and application of "drilling observation" geosteering contingencies in landing the well at the heel target and maintaining the planned productive interval placement within the Monterey interval.

3. The static reservoir pressure was not well defined, with a large range of observations from 3200 to 5200 psi. This unknown presented many design complications and had to be better defined before the optimum MPD well construction methodology and related well attributes were finalized.

Once these critical elements were examined, all other aspects of the well design were reviewed. A review of tasks and pursuits for team members is provided in Appendix A.

The well's pre-spud meeting was conducted in Bakersfield, CA, in January 2004. The final well design was confirmed and the well programming/service company requirements assigned. A copy of the basic well program is presented in Appendix B. Many design elements were reduced in scope due to significant capital budget constraints. The major alterations are summarized as follows:

1. Conducting a new VSP seismic survey was delayed to a later project phase since the viability of the technology was seriously questioned. Nearby field tests of the technology had been disappointing as reported from Thums field experience.

2. Rather than re-enter the existing delineation well, the surface location would be twinned with a new, larger surface hole. Although this added capital expense, it was deemed necessary for many operational concerns.

3. Priority was placed on placing the 7-in. liner into the top of the high-resistivity Monterey target as quickly as possible to mitigate concerns regarding hole stability, as evidenced in the two previous wells. An inhibited water-based system rather than an oil-based mud (OBM) was deemed acceptable given the larger than normal hole size design. This design provided extra clearance for the 7 -in. liner in the $95 / 8$-in. intermediate section. The water-based fluid choice would also allow for more precise hydrocarbon observation of entering the top of the high-resistivity Monterey heal target in the upper curved interval. 
4. Due to costs constraints, all evaluation activities were curtailed to a minimum, including the option for evaluation logging and/or coring in the horizontal interval.

5. The main geosteering observations of fracture access in the lower curve and productive interval would be deduced from penetration rate, cuttings description and hydrocarbon in-flow observations. This approach is termed "evaluation-while-drilling" (EWD). A bottom-hole pressure sensor would be employed on the MWD/LWD package in the productive interval to confirm that the balanced to under-balanced state was being effectively generated by air injection.

6. Rather than employ an expensive nitrified drilling fluid in a conventional UBD mode, a novel air injection concentric slave string MPD system was designed as discussed previously. The solids-free water-based drill-in fluid had special additions to stabilize the shale, reduce corrosion concerns and ease disposal. Successful application of this system is detailed in this report.

Continued capital constraints and lack of rig availability significantly delayed the start of drilling operations. A special component for the 7-in. slave string (a check-valve sub) was never made available from the service supplier, which further complicated the surface casing design, and delayed the development of MPD operational procedures. Drilling operations commenced on September 12, 2004 and were terminated on November 11, 2004. The vertical and upper curved sections were drilled and lined through the problematic shale member without major stability problems. The top of the high-resistivity Monterey was thought to be seen at the expected TVD of $10,000 \mathrm{ft}$ where the 7 -in. liner was set at a $60^{\circ}$ hole angle. Significant observations of oil and gas suggested the fractured interval anticipated at the heel location had been penetrated.

Post-well mud-log analysis could be interpreted to suggest that the top of the high-resistivity Monterey was not seen at this point. Instead, a fault or fracture up into the upper Monterey had been crossed. The high gas show was thought at the time to be proof of high-resistivity section of the Monterey, as this gas show is never seen in the upper Monterey in the area. However, this interpretation of penetrating the high-resistivity Monterey at this depth was increasingly challenged as drilling progressed since cuttings recovered from below the 7 -in. shoe lacked the dolostone and chert expected, and the drilling rate was faster then expected with a PDC bit. (See the geologist's post-well summary report in Appendix D.)

The original design envisaged lining the upper curve at an $80^{\circ}$ angle into the mid section of the high-resistivity Monterey shale interval at near 10,150 TVD. The curve was terminated and lined at a higher TVD and lower angle $\left(60^{\circ}\right)$ to allow open-hole production contribution from the observed fractured interval at the heel of the well. Build capability and penetration rates were poor in the upper curve. The smaller bit to be used below the 7-in. liner was expected to allow faster construction of the lower curve to the designed $80^{\circ}$ productive interval angle.

A total of $2572 \mathrm{ft}$ of $61 / 8$-in. open near-horizontal interval was placed in the shale section, passing the original well's bottom-hole location and extending the planned well length by approximately $470 \mathrm{ft}$ along the intended trajectory. The $61 / 8$-in. lower curve was not built as originally planned below the 7 -in. liner shoe. Instead, a $\pm 250 \mathrm{ft}$ tangent section was drilled at a $62^{\circ}$ angle to further penetrate into the high-resistivity Monterey mid section. This was followed by the planned lower curve drilled up to an $80^{\circ}$ angle and gradually increased to near $90^{\circ}$ at final TD. Very little hydrocarbon in-flow was observed of fracture crossing along the mid-length of the productive interval. This may be a result of the well trajectory falling underneath the Monterey highly 
fractured zone along the mid-length portion. Alternatively, the wellbore may have been above the high-resistivity Monterey due to a down-thrown structural feature possibly seen at the heel of the well.

Hydrocarbon observations, cuttings analysis and gamma-ray response indicated additional fractured intervals were accessed along the last $\pm 900 \mathrm{ft}$ of well length at the toe. The well was completed with a $27 / 8$-in. tubing string set in a production packer at $9250 \mathrm{ft}$ in preparation for flow and swab tests to be conducted later by a service rig. Planned and actual horizontal well paths are compared in Figure 5.

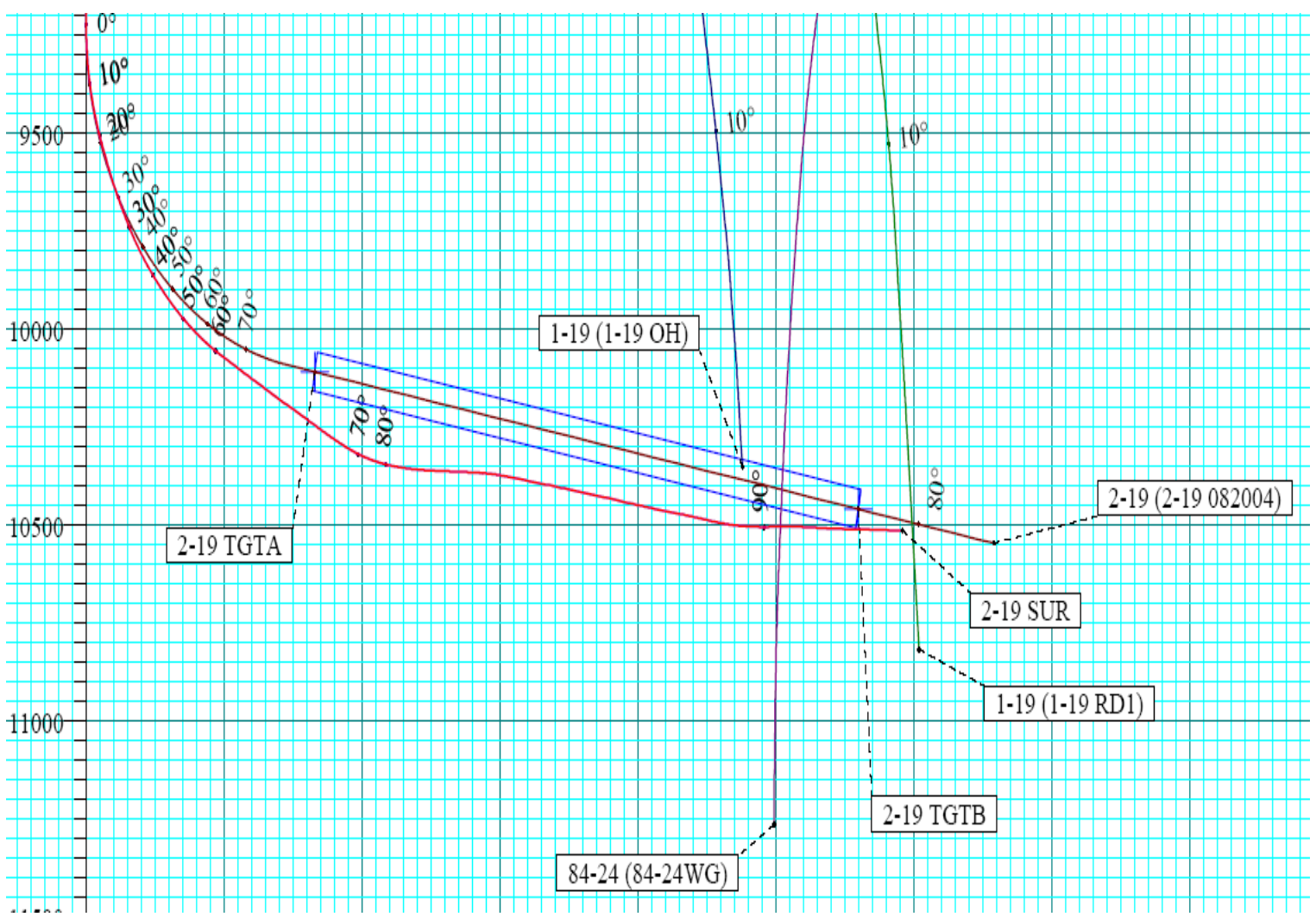

Figure 5. Plan (blue) and Actual (red) Well Paths

The planned well time was estimated at 39 days and overall cost as $\$ 2.4$ million. Actual results are 66 days (Figure 6 ) at a total cost of $\$ 3.4$ million. 


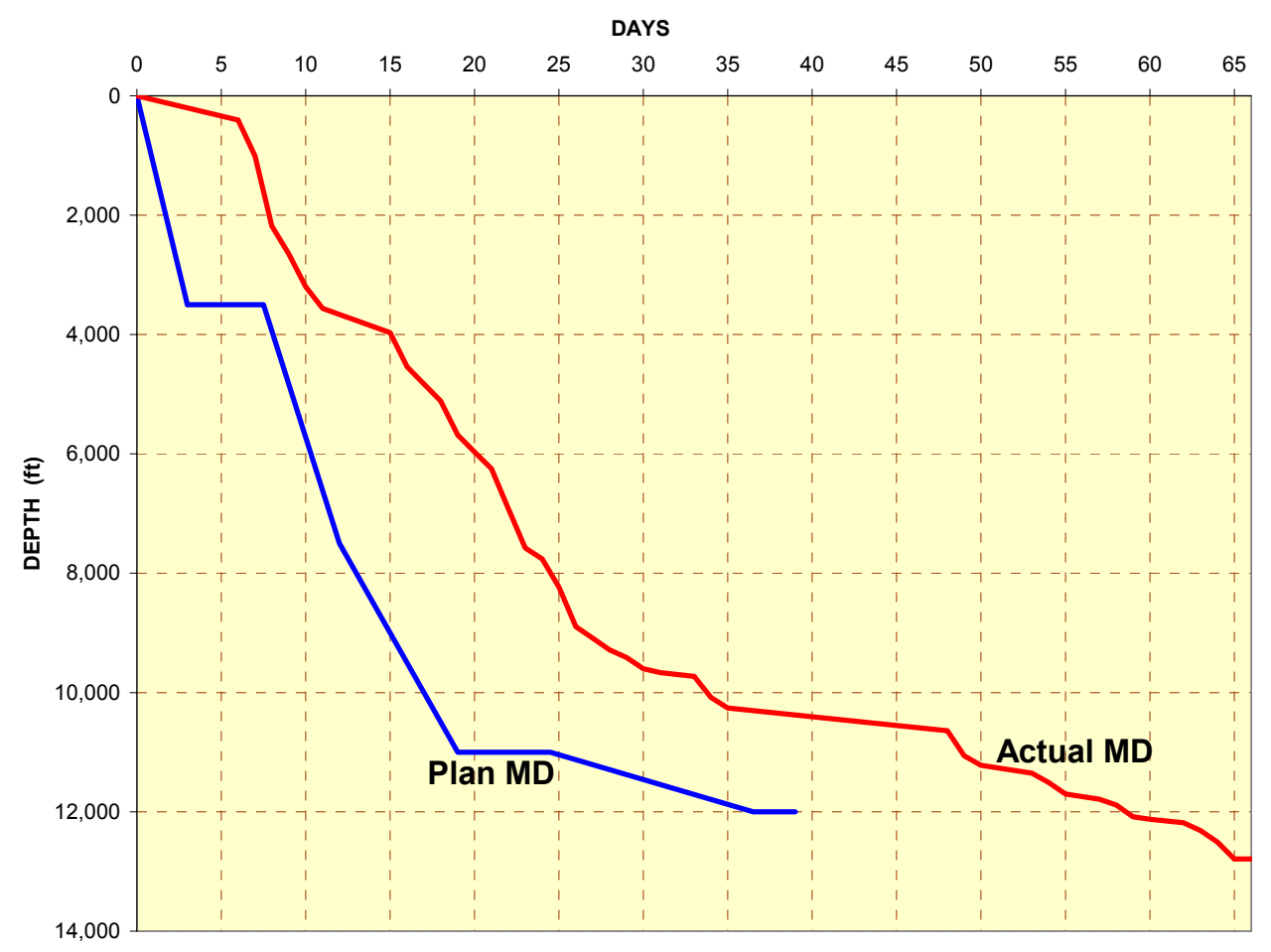

Figure 6. Plan and Actual Time/Depth Curves

Productivity responses during subsequent flow and swabbing tests were negative. The well failed to inflow and only minor amounts (a few barrels) of light oil was recovered when swabbing the well down to a depth of $8500 \mathrm{ft} \mathrm{TVD.} \mathrm{(This} \mathrm{would} \mathrm{have} \mathrm{lowered} \mathrm{the} \mathrm{bottom} \mathrm{hole} \mathrm{pressure}$ (BHP) to less than 1500 psi.) The lack of production seen at this low BHP may suggest that the actual sustainable reservoir pressure is far less than anticipated. The operator is currently investigating the costs and operational viability to re-enter the well and conduct an FMI (fracture detection) logging run and/or an acid stimulation. No final decision or detailed plans have been made regarding this potential intervention at this time. 


\section{Experimental}

\subsection{Task Statement}

This project includes planning, drilling, testing, and producing one or more wells in the Los Alamos Prospect in the Santa Maria Basin of California using innovative managed-pressure drilling (MPD) techniques. Specific tasks (as originally proposed) are summarized below.

\section{Task 1 - Technical Meeting}

The first phase (Budget Period 1) of the work will be to perfect the details of the drilling, completion and cost plan of the project through a meeting with the primary sub-contractors for the project. These sub-contractors are Maurer Technology, Sugar Land, Texas; Weatherford International, Inc., Houston, Texas; Scientific Drilling, Bakersfield, California; and Imke Consulting, Bakersfield, California. Maurer Technology will provide overall coordination and expertise as to the underbalanced and horizontal phases of the project. They will provide consultants and well-site supervision for these technologies during this phase of the project. Weatherford International will provide cutting-edge underbalanced drilling technology, equipment and personnel during the horizontal phase of the project. Scientific Drilling is one of the foremost providers and developers of directional drilling equipment and expertise worldwide, and will provide these services, equipment and personnel during all phases of the drilling operation. Imke Consulting will provide the overall well planning, well services and overall wellsite supervision. They will be responsible for coordinating the phases of drilling and completion.

\section{Task 2 - Redrill and Complete the Primary Project Well}

Subject to adjustments, updates and modifications resulting from the technical meeting discussed under Task 1 of the project, a drilling and completion plan involving five subtasks is expected:

\section{Task 2.1 - Plug Back the Well to be Redrilled}

The existing Temblor well which is cased to $11,400 \mathrm{ft}$ needs to be plugged back to the base of $95 / 8$-in. surface casing at $3520 \mathrm{ft}$, and a kick-off plug set. This work will be accomplished with a workover rig prior to moving the drilling rig on location.

\section{Task 2.2 - Drill into the Top of the Monterey Formation and Log}

An $83 / 4$-in. hole will be directionally drilled with some $9^{\circ}$ of westerly deviation to approximately $9000 \mathrm{ft}$. This portion of the hole will be drilled through the Sisquoc formation with oil-based mud to prevent clay swelling and associated problems with the Sisquoc. It is planned to use a topdrive rig, if available, for all phases of the drilling operation to save drilling time and give "uphole" rotation ability, if needed. It is planned to use PDC bits through the Sisquoc. At this point the well will be drilled directionally in a northwesterly direction until an $80^{\circ}$ deviation is reached in the high-resistivity portion of the Monterey. This portion of the hole will also be drilled with oilbase mud, PDC bits in the Sisquoc, and hard formation insert bits in the Monterey. 
Task 2.3 - Run and Cement 7-in. Casing in the Monterey

It is planned to run a string of 23,26 and $29 \#$ casing to TD and cement to $3000 \mathrm{ft}$ above the shoe. A Weatherford downhole deployment valve tool will be set in the casing string at approximately $3000 \mathrm{ft}$ depth.

\section{Task 2.4 - Drill Horizontally and Underbalanced 1000 ft in a Northwesterly Direction}

A $6 \frac{1}{8}-$-in. hole will be drilled northwesterly $1000 \mathrm{ft}$ with an $80^{\circ}$ deviation to the approximate bottom-hole location of the existing Oxy well. This portion of the hole will be drilled underbalanced using crude oil or a similar lightweight drilling fluid. If oil or gas enters the bore hole, it will be allowed to flow freely to the surface and separated through a rotating control head $(\mathrm{RCH})$. Gas will be flared and oil sent to temporary storage tanks. It is planned to use a Weatherford actively energized RPM-3000 rotating control head and a four-phase UBD separation system in this phase of the operation. Hard formation insert bits will be used in the Monterey. After drilling out the shoe of the 7-in. casing and before commencing the underbalanced operation, a full-diameter core will be cut for $15 \mathrm{ft}$ to $30 \mathrm{ft}$ to facilitate analysis of the fractured reservoir. After reaming the cored hole, a drill-stem test will be conducted with packer set in the base of the 7-in. casing to determine to the degree possible the true reservoir pressure. This will allow selection of the best design, equipment and drilling fluid for the horizontal phase of the operation. Trips for bit changes or other reasons will be made without killing the well by use of the downhole deployment valve (DDV).

\section{Task 2.5 - Install Wellhead and Tubing for Production as Open Hole Completion}

Again, the wellhead and tubing will be installed without killing the well using the downhole deployment valve.

\section{Task 3 - Produce and Test Primary Project Well}

The well will be produced and tested at various rates and choke sizes to determine productive capacity and duration. The rates tested will depend on a combination of factors, including the behavior of the well while drilling underbalanced. In general, it will be produced at lower rates initially, regardless of its indicated productive capacity. Only oil will be marketed since there is no gas pipeline presently available. The oil will be trucked to market in Santa Maria, Ventura or Bakersfield. Produced gas will be flared, for which there are permits.

\section{End of Budget Period I / Decision Point.}

\section{Task 4 - Conduct and Analyze VSP Survey}

A vertical seismic profile (VSP) survey will be conducted and analyzed after the first month of production on the primary well and will be incorporated in the selection of the next wells to be drilled.

\section{Task 5 - Drill, Test and Produce Additional Horizontal Wells from Same Location}

If production testing on the first well proves successful, and an economic discovery is indicated, a second horizontal well will be drilled. The location of the second well would probably be 
immediately east of the first and nearly vertically under the well site. Results of the Sonic LWD tool and the VSP survey would also be incorporated in this decision. If the rate of penetration was sufficient in the first well and other complications were not encountered, the second well might be drilled horizontally for 1500 or $2000 \mathrm{ft}$. The second well would be production tested for a similar amount of time as the first well, and then a third well drilled. If the third well were successful, then it would probably be planned to drill several more wells continuously at locations best suited to help define the field. It is possible that some of the wells would be of greater length and that perhaps 10 to 12 horizontal wells would be the optimum number to efficiently produce the reservoir. During the development phase of the project, reservoir studies would be continuously performed and evaluated to help make this determination.

\subsection{Drilling Objectives}

The Temblor Deep Fractured Monterey project's primary objectives were divided into three categories:

1. Verify the extent of fracturing/micro-fracturing in the subject block of the deep Monterey shale. This goal has been met but with disappointing production results.

2. Drill the subject zone at (or near) a horizontal attitude in an underbalanced condition with due regard to HS\&E concerns. This goal was met, proving the viability of horizontal wellbores and MPD techniques for the deep high-resistivity Monterey shale member.

3. Complete the well and measure potential production relative to estimated volumes of oil in place. This goal was met but the observed lack of reservoir deliverability is disappointing. Possible well intervention/stimulation options are currently under review.

Other issues pursued by the project included:

$>$ Maintaining the stability of the problematic Sisquoc shale member above the highresistivity Monterey target

$>$ Ability to conduct MPD drilling in this setting, and the ability to conduct "evaluate-whiledrilling" into and within the Monterey target

$>$ Successful application of PDC bits in the shale sections

$>$ Improvement seen in penetration rate delivered by MPD drilling methods

$>$ Economically and environmentally acceptable disposal of the drilling fluid and cuttings with an inhibited water-based drill-in fluid that can mitigate shale stability concerns

Each of these topics is discussed below and in Section 4. 


\subsection{Shale Stabilization}

The high-angle productive open-hole section of the well was successfully drilled with water containing a $\mathrm{KCl}$ substitute (i.e., tri-ethylene methyl chloride) to:

1. Stabilize the shale

2. Allow visual inspection of cuttings for micro-fractures, and gas or oil in the microfractures

3. Limit disposal problems associated with drilling fluids and cuttings containing $4 \%$ salts

4. Control corrosion on the drill pipe and casing

\subsection{MPD Operations}

Managed-pressure drilling (MPD) operations on the well were accomplished by pumping air through a concentric casing string (slave string) set at about $3300 \mathrm{ft} \mathrm{TVD} \mathrm{(Figure} \mathrm{7).}$

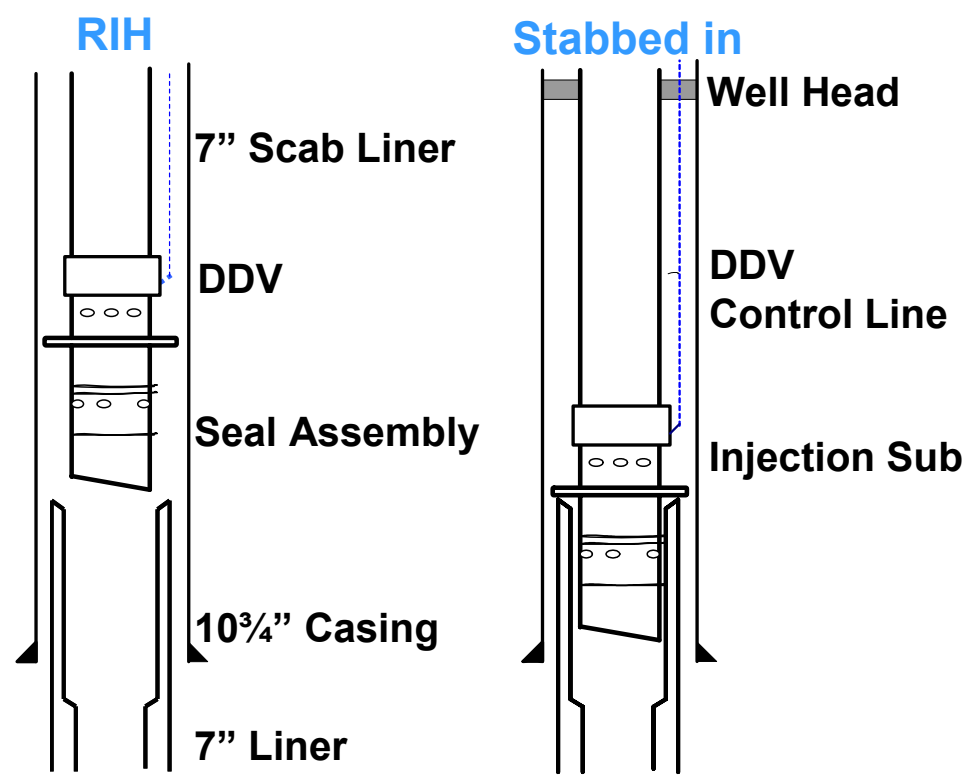

Figure 7. Liner and Slave String Design 


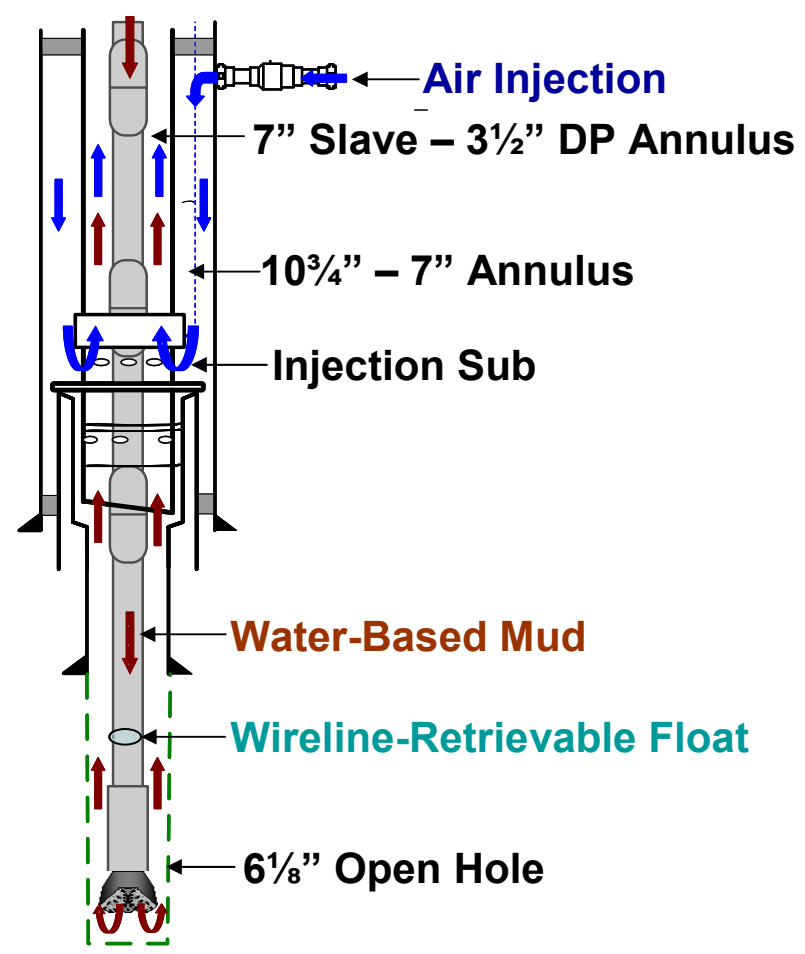

Figure 8. Slave-String Fluid Paths

This system was employed to:

1. Allow the use of air instead of nitrogen by eliminating the problem of corrosion in the hot Monterey section

2. Allow the use of conventional MWD and LWD mud pulse tools by keeping the air out of the drill pipe

3. Increase drilling rate as the differential pressure between the wellbore and formation decreased and became negative

4. Allow EWD observations of hydrocarbons while drilling

Several techniques were combined to enhance safety at the drill rig when drilling in a balanced to underbalanced state including:

A down-hole deployment valve (DDV) was installed in the 7-in. slave string near $3000 \mathrm{ft}$. When the drill bit was pulled up above the valve, it could be closed to isolate the top of the hole from any down-hole pressures. This would allow the last $3000 \mathrm{ft}$ of drill pipe to safely be pulled from the hole on trips without killing the well.

$>$ A closed separator system was employed to contain oil and gas fumes from the drilling fluid before they were sent to the flare.

> A shielded flare (Figure 9) was employed to avoid the visual impact of a bright flare next to a major highway and three burner heads were used to avoid supersonic rumble from the flare. 


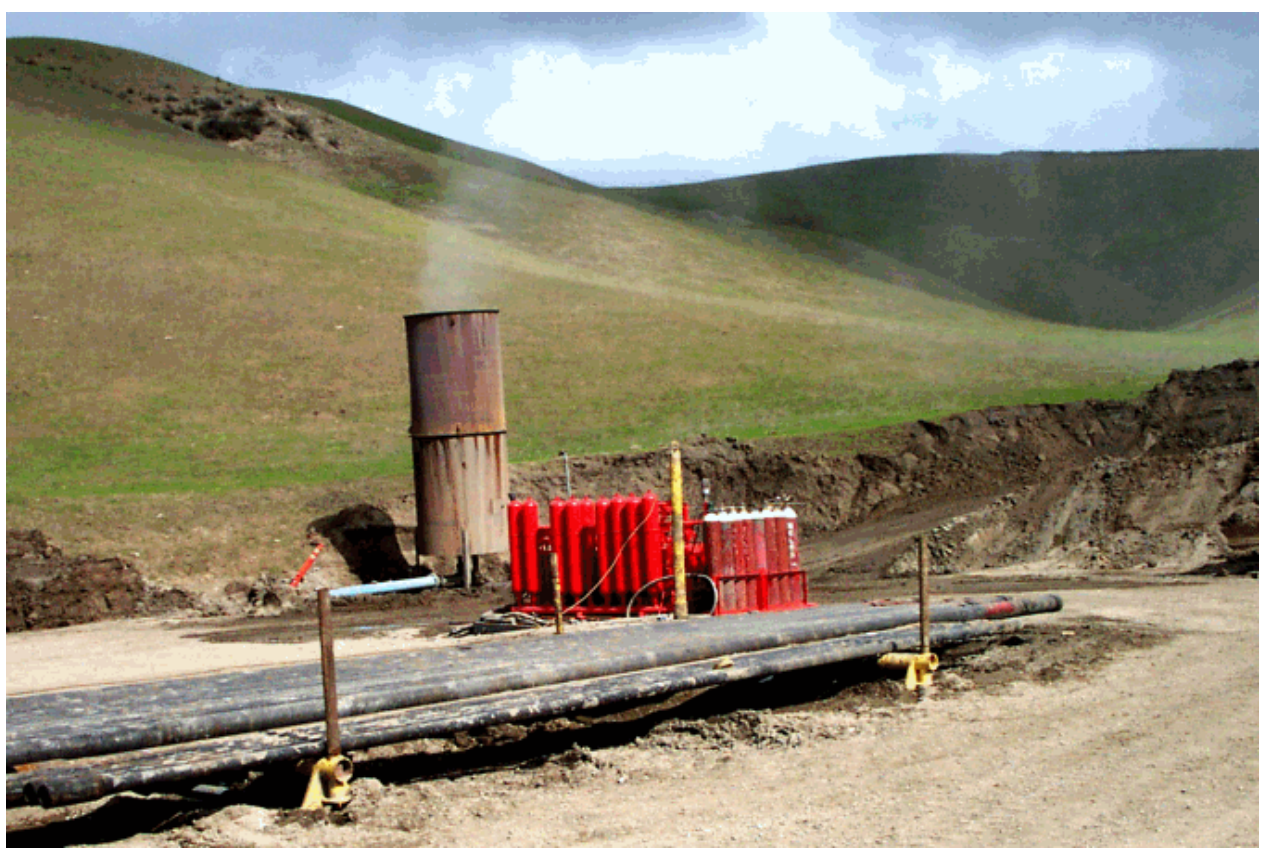

Figure 9. Flare System

Drill bits in the deep Monterey in the previous wells had generally been limited to insert-type tricone bits because of dolomite/silicate streaks, although some evidence from nearby workover operations indicated that PDC bits may be worth pursuing in this application.

The hole was completed open hole to simplify the completion and allow future capability to further investigate open fractures as indicated by offset well data and drilling observations. 


\section{Results and Discussion}

\subsection{Summary of Progress by Task}

\section{Task 1 - Technical Meeting}

Several meetings were held with project team members to plan the well and field operations. Minutes of planning meetings are provided in Appendix A.

\section{Task 2 - Redrill and Complete the Primary Project Well}

The project was modified because the re-entry was deemed to be much less attractive than drilling a new hole (as discussed previously).

Task 2.1 (Modified) - Drill Oversized Surface Hole, Set and Cement Casing

The surface hole was successfully drilled and cased without significant incident. A complete discussion of all drilling operations and results for all well sections from surface hole to final TD is provided in Appendix C.

Task 2.2 (Modified) - Drill 97/8-in. Intermediate Hole and Upper Curve into Top of Monterey Formation

The upper curve was drilled and lined with 7-in. liner without major hole-stability problems. The top of the high-resistivity Monterey target was clearly seen by drilling observations at the expected TVD of 10,000 ft. Drilling rates were poor with rock bits, but improved with PDC bits. Significant rig time was lost due to rig problems, and failure of the primary cement job on the 7in. liner. The liner was successfully cemented via a remedial squeeze operation. An adequate cement top was confirmed behind the liner by a temperature survey. The 7 -in. liner was set higher then planned at a $60^{\circ}$ angle just into (50 ft) the high-resistivity Monterey target. This was done to allow production from an observed fracture set at the Monterey top; to allow for a smaller bit size in the lower curve to generate faster drilling and build rates up to the planned $80^{\circ}$ horizontal angle; and to permit lining of the exposed intermediate section before shale stability became a problem.

\section{Task 2.3 (Modified) - Drill Productive Interval 10,258 ft to 12,789 ft}

A total of $1061 \mathrm{ft}$ of $61 / 8$-in. open-hole tangent and lower curve were drilled in three days using the MPD slave string air-lift method described. The main horizontal section was then drilled from 11,319 to $12,789 \mathrm{ft}$ passing the original discovery well's bottom hole location at the planned TVD. Numerous trips were made for failed motor/MWD components and rig repairs. Good oil and gas shows were seen over the last $900 \mathrm{ft}$ of open hole, and fracture crossings were suggested by MWD gamma-ray response. A PDC bit run was very successful but a second run failed, likely caused by MWD junk in the well. Subsequent rock bit runs delivered comparatively poor drilling rates and footage results. 
Hole stability was good throughout, and MPD operations were successful in lowering BHP to the targeted range, confirmed by a BHP MWD pressure sensor. Reduced BHP also correlated with improved drilling rates.

\subsection{Shale Stabilization and Disposal}

A basic challenge for wells in this area is stabilization of the deep Monterey Shale to protect the integrity of the hole and to allow cuttings to return to the surface in good condition for evaluation while drilling. This implies an inspection of drilled cuttings for micro-fracturing and oil within the fractures, and is calibrated with mud-gas logs, changes in drilling, etc. The target high-resistivity section of the Monterey is a gradation between chert, argillaceous chert and siliceous shale and should not require stabilization. The bounding upper and lower Monterey units are less siliceous and thus shale stabilization may be attractive in theses intervals.

Typically, shale is stabilized by adding $4 \% \mathrm{KCl}$ to the drilling fluid. Unfortunately, a concentration of $4 \% \mathrm{KCl}$ also represents the point of maximum corrosion of the tubulars. This much salt also requires special drilling waste disposal procedures.

Problems with $\mathrm{KCl}$ were successfully resolved on the demonstration well by using a $\mathrm{KCl}$ substitute - TEA (triethanolamine) - at a concentration of $0.1 \%$ by volume in the drill-in fluid. The material has a residual chloride ion content of only $165 \mathrm{ppm}$ as opposed to $2000 \mathrm{ppm}$ with $\mathrm{KCl}$. And unlike $\mathrm{KCl}$, TEA does not require extensive use of corrosion inhibitors.

TEA was first reported for use for shale stabilization in Saudi Arabia. In the last three years it has been used experimentally by ENCANA Oil Company in the Denver Julesburg Basin. TEA kept the hole in good condition in the productive/horizontal interval. There was no trouble with shale stabilization, and cuttings, while very small, did not appear to be significantly hydrated or altered. The geologist's ability to observe mineralogy associated with fractures, and hydrocarbon staining were not affected by this drill-in fluid design.

There were significant cost savings by minimal use of corrosion inhibitors accompanied by no apparent corrosion of the drill pipe. Drill cuttings and spilled mud were disposed of by the SoliBan technique. This system uses proprietary material to solidify the cuttings and slop mud using an exothermic process that, when set, has minimal leaching. This allowed the well cuttings to be piled into a hill, seeded and left on location instead of being hauled to a disposal site. Drilling fluid waste from the well was primarily water with no salt.

\subsection{MPD Methods and Techniques}

The well was to be drilled with pressures maintained via managed-pressure drilling (MPD) techniques in a balanced to underbalanced condition to avoid major damage to the reservoir from drill solids plugging and water blocking, to optimize EWD, and to increase drilling rate. Bottom-hole pressures were maintained as planned. EWD observations appeared adequate in detecting oil-laden fracture crossings.

Drilling rates in previous wells (which employed relatively heavy muds) were very slow. Both theory and practice indicated that a significant increase in drilling rate would be expected as the 
wellbore pressure was reduced to equal or below formation pressure. This was clearly demonstrated in this demonstration well (Figure 10). Since formation pressure was never firmly established, it is difficult to assign a calculated value to the drilling rate vs. differential pressure equation. In general, however, the improvement in drilling rate appeared to follow the trend of the "d" exponent of Jordan and Shirley.

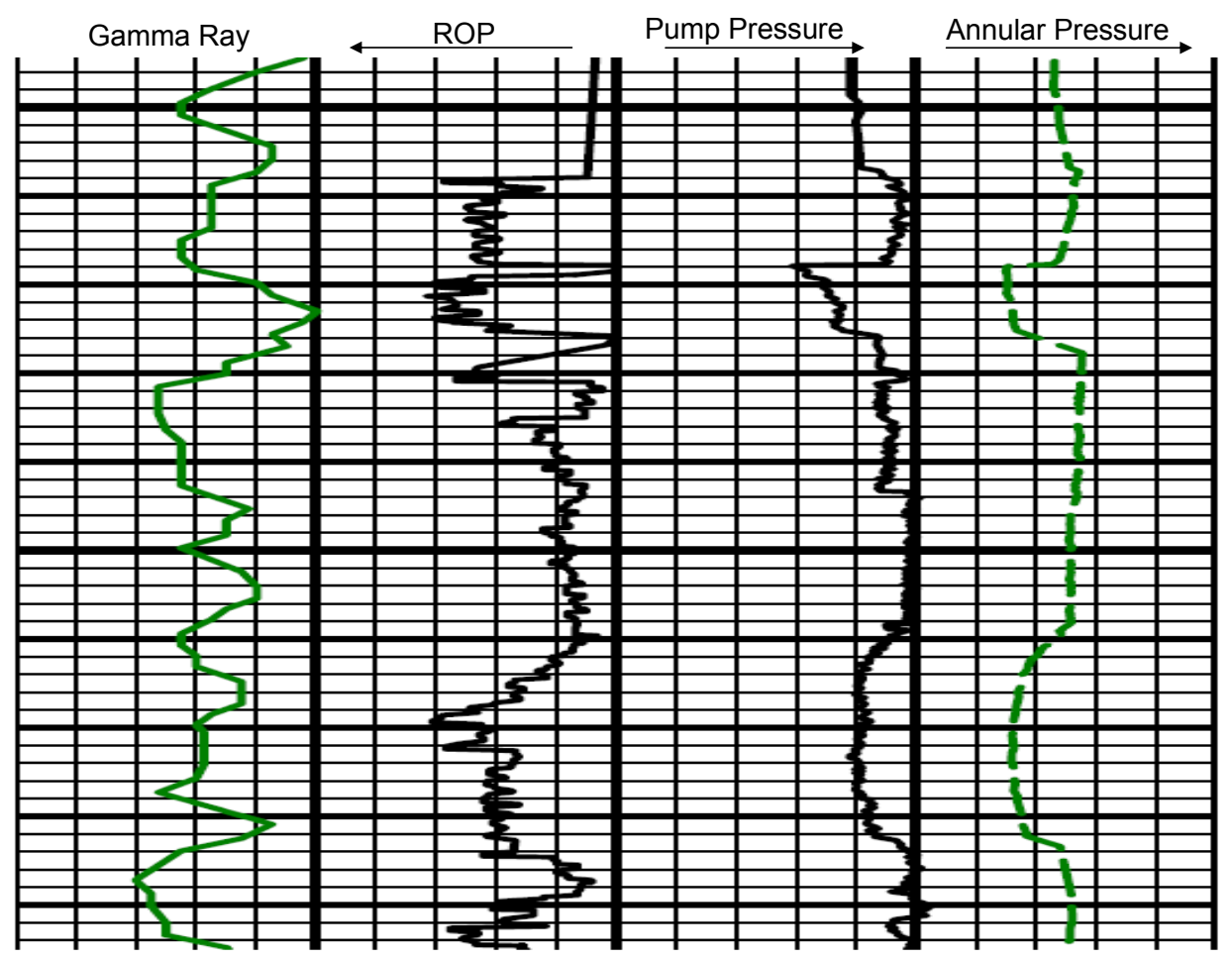

10300

Figure 10. Impact of Pressure on ROP

There are a number of MPD techniques that could have been used to maintain the balanced to underbalanced pressures. The concentric annulus method was chosen because it allows the use of mud-pulse MWD; minimizes corrosion in the deep, hot hole; minimizes the effect of injected gas on the formation and cuttings; and eliminates the need to use expensive nitrogen as the gas phase. The larger hole required for this system also allowed the retrievable placement of the DDV and related control lines.

Air was injected into this concentric annulus. The air unloaded about half of the treated water in the annulus between the drill pipe and 7-in. slave string, which reduced bottom-hole pressure about 460 psi (665-psi loss in hydrostatic pressure plus a 200-psi gain in friction pressure). After the original UBD service provider supervisor was replaced, and air rates and backpressure maintained as originally planned, the MPD operation was smoothly implemented.

MPD operations were successful in maintaining the targeted bottom-hole pressure while drilling. This performance was evidenced by surface and bottom-hole pressure observations, as well as oil and gas out-flows. However, no major hydrocarbon in-flow was observed at any time during drilling, and a lack of reservoir pressure resulted in no need to employ the DDV during trips. 


\subsection{Productivity Results}

The lack of well productivity to date is discouraging. The apparent conclusion is that the reservoir does not contain significant open fractures, and/or the lack of micro-fractures in the matrix cannot provide pressure support to recharge the fractures at an economical rate. This appears to be true in the original vertical wells and may have been repeated in this nearhorizontal application. This conclusion is supported by the well's behavior during all MPD operations.

Evaluation while drilling (EWD) of this application appeared to be very successful and useful. Once cuttings recovery procedures were adjusted for MPD operations, the geologists indicated that the samples were relatively clean and easy to interpret, although finer then seen in vertical well applications. As MPD operations were stabilized, mud-gas logging improved, with very good samples seen from the toe of the well. The originally interpreted top of the high-resistivity Monterey target was easily observed by gas/oil shows, cuttings description and penetration rate variation. As discussed, whether this was actually the top of the high-resistivity section of the Monterey or a hydrocarbon-filled fault zone, remains a subject of debate. Observations of oilfilled fractures were likewise relatively straightforward in the productive interval.

The fact that the mid-length of the well may be slightly below the highly fractured Monterey interval does not solely explain the lack of productivity seen to date. The high-resistivity Monterey was expected to be relatively thick (300-500 ft). If the vertical extent of natural fractures is confined to a significantly thinner target interval, then the oil storage and deliverability potential of the reservoir are likewise significantly reduced. If that is the case, having 600-900 ft of additional productive length would not likely have salvaged the well's productivity. The best scenario to prove otherwise may be to re-enter higher up in the well to drill a vertical pilot and attempt to confirm the exact level and extent of the high-resistivity Monterey, then re-enter the open heel of the well and drill a second length of productive interval higher in the target formation.

Capital cost constraints experienced during well planning led to a decision to perform no evaluation logging on the well other than the EWD conducted. In retrospect, a suite of wireline logs or cores may have been of value in confirming the location of the well and actual reservoir characteristics. These data may have also helped define the viability and optimum design of any future stimulation or damage removal options for the existing well. However, the team is relatively confident in the general accuracy of the EWD conducted. It is concluded that this level of evaluation was adequate for the base objectives of the well. It is also believed that the interpretation stemming from that effort is sufficiently reliable to support the team's explanation for lack of well productivity.

Other possible explanations for the lack of well productivity include:

$>$ There are no significant naturally fractured or highly micro-fractured intervals accessed by the horizontal section (although many drilling observations indicated that oil-filled fractures were crossed).

$>$ The reservoir was significantly damaged during drilling operations (although a nondamaging, solids-free, water-base fluid was employed in a MPD mode). An emulsion block from the water/oil mixture is suggested as a possible damage mechanism. 
$>$ The well collapsed at the open-hole heel, blocking production (although drilling observations indicate a stable and gun-barrel hole in a very tight and competent shale member). During subsequent swabbing tests a sinker bar was run on a slick line to a measured depth of 10,239 ft at a $60^{\circ}$ angle. This is about $23 \mathrm{ft}$ below the bottom of the 7-in. liner shoe in open hole.

\subsection{Field Execution}

The final well design proved to be effective in meeting project objectives; all basic technical goals were accomplished. However, well productivity was disappointing and well costs were significantly above the original estimate. After analyzing the overall operation, the project team believes that the most significant improvements that could be applied to this application in the future are related to field execution of the project plan. Although nothing can be (or could have been) done to mitigate geologic risks, better field execution of the plan may have resulted in less apparently unproductive hole section in the middle of the horizontal interval, and perhaps more cost-efficient operational performance in the field.

A significant factor that reduced the efficiency of field operations was a large time delay (six months) between the pre-spud meeting and commencement of field operations. Detailed discussions and plans were developed for all novel aspects of the application during the well planning stage. However, the time delay resulted in key well-site supervision and service provider personnel involved in the planning not being available for field operations. A reliance on key service providers to provide site supervision and programmed procedures was only weakly fulfilled. Various key MPD equipment components suggested by the service provider were unavailable once field operations commenced. These circumstances led to a gap between the well plan and field execution. Key personnel who were not active in both the prespud meetings and field operations included the drilling contractor site supervisor, the operator's well-site supervisor, and the UBD well-site supervisor.

Drilling time sheets maintained by the crew indicate that total problem time experienced on the well officially accounted for only $3.8 \%$ of total field operations. However, the definition of problem time used here is very subjective. From the project team's perspective, there was a larger proportion of time lost due to avoidable errors and less than optimal operational decisions made on site. Delays were primarily due to a combination of:

1. Slower than anticipated penetration rates in both the intermediate and productive hole sections. The merit of PDC bits appeared attractive in this application. This was made evident by the superior performance of this bit type in both the intermediate and productive sections. Application of PDC bits was not seen as attractive by the operator's site-supervisor. The decision to running the last PDC bit (\#8) after observing possible MWD junk in the hole (Allen screw) may have led to premature failure of this last PDC bit. PDC bit runs in the intermediate section are apparently very worthwhile. The degree of improvement seen with PDC's in the horizontal section is more difficult to evaluate due to the possible variation in rock types drilled by PDC's as compared to rock bits.

2. Slower than expected rig operations with numerous equipment failures, and extended liner and tie-back operations stemming from a failed primary cementing job and a spaceout error in placement of the slave string. The drilling contractor places significant focus 
on HS\&E operational policies. This focus is admirable with respect to safety concerns. From some team members' perspective, however, rig operations appeared to be conducted very slowly. Even with a relatively slow and methodical pace of rig activity, many avoidable operational failures occurred. The drilling contractor's HS\&E policy would not permit tripping out of the productive interval without first filling the hole with the water-based dill-in fluid. This policy appeared to negate the potential use and benefit of the DDV. Given the observed lack of reservoir pressure exposed throughout the productive interval, this point was moot from a field operations perspective, and thus the issue was neither stressed nor pursued.

3. Numerous trips for failed motor and MWD assemblies in the productive interval. The expected bottom-hole temperatures of $250-260^{\circ} \mathrm{F}$ were discussed with the service provider with respect to motor requirements during the pre-spud meeting. Unfortunately, there did not appear to be an adequate supply of appropriately designed and serviced motors, resulting in a high frequency of motor/MWD failures on the well. 


\section{Conclusions}

Based on an analysis of field operations and results for the demonstration well to employ managed-pressure drilling (MPD) techniques to drill and produce oil and gas from the fractured Monterey in the Santa Maria Basin of California, the project team developed the following conclusions and recommendations:

1. MPD applications incorporating horizontal wellbores are viable in these deeper highresistivity Monterey targets. The existence of conductive fractures/micro-fractures and sustainable dual-porosity reservoir pressures are most likely prerequisites for success.

2. TEA drilling fluids were applied successfully here and should be applied in similar Sisquoc and Monterey shale applications. This additive mitigated corrosion, provided adequate shale inhibition, provided good cuttings, and eased cuttings disposal efforts. OBM is not a unique requirement for stable hole sections in these Miocene sequences. This well had the Sisquoc top exposed to open-hole operations for a period exceeding 16 days, with no major stability problems observed.

3. The proprietary Soli-Ban technique of waste disposal merits further application in this general setting.

4. Novel MPD drilling modes should be given expanded application in this general setting. This drilling method provided good capability for evaluation while drilling, faster penetration, and minimal concern for formation damage.

5. Application and customization of PDC bits should be more aggressively pursued in deep Monterey drilling projects.

6. It is critical to ensure the continuity of key staff members between planning and field operations phases. Properly briefed and adequately relieved field supervision (with 24hour coverage) is a necessity when conducting novel well-construction operations. Field supervisors must strive to ensure that an open and effective "team" effort exists, particularly when novel operations are employed.

The lack of oil/gas production observed even though bottom-hole pressure was reduced via swabbing to less than 1500 psi, may suggest that the actual sustainable reservoir pressure is far less than anticipated. Temblor is currently investigating costs and operational viability to reenter the well and conduct an FMI (Formation Micro-imager for fracture detection) logging run and/or an acid stimulation. No final decision or detailed plans have been made regarding this potential intervention at this time. 


\section{References}

(No references cited herein.) 


\section{Appendix A}

\section{Temblor-Los Alamos DOE Demonstration Project Meeting Notes (1) Bakersfield, CA - October 8, 2003}

\section{Executive Summary}

The first technical and preliminary well design meeting on this project was held at Temblor offices in Bakersfield on October 8, 2003. In attendance were:

$>$ George Witter, Temblor Petroleum, Primary Operator and Project Manager.

> Harold Imke, Imke Consulting, Operations Engineer responsible for service selection and contracting, and all field operations contracting and supervision.

$>$ Bob Knoll, Maurer Technology, Well Design Team Leader, also responsible for field operations monitoring, all project documentation and report generation for management edit/approval, technology transfer presentation generation and delivery assistance as required.

$>$ Dennis Wood/Jim Stanley, Weatherford, underbalanced drilling (UBD) service provider.

Objectives of the one-day meeting were to:

1. Define/confirm primary and secondary project objectives

2. Introduce the overall geologic and operational setting and historic well construction/production experience to date

3. Outline key project risks and related technical pursuits to mitigate same

4. Define key project team members and responsibilities of each during the various tasks of the project

5. Generate a go-forward action plan with specified tasks and milestones goals/dates

The basic objective of the project was confirmed - proving economic exploitation of the Los Alamos, High Resistive Monterey (HRM) formation by optimum fracture access with a horizontal well constructed with UBD. The well would be completed open-hole to minimize productivity impairment of the highly fractured target zone. Following an overview of the geologic setting and field experience, three critical aspects of the application were identified as follows:

$>$ Problematic shale and related hole problems must be mitigated in the main tangent and curve section.

$>$ Significant geologic (structure) uncertainty exists in this application. Optimum placement of the lower curve/heel of the well into the Monterey target at $\pm 10,000 \mathrm{ft}$ TVD will require definition and application of geo-steering contingencies in landing the well. 
$>$ Static reservoir pressure is not well defined, with a large range of observations from 3200-6000 psi. This unknown presents many design complications and must be better defined before the optimum UBD well construction methodology and related well attributes are finalized.

Once these critical elements were examined, all other aspects of the well design were reviewed. A series of technical pursuits was defined and related tasks assigned to the members of the team. It is intended that a detailed well design meeting with all team members and key service suppliers will be conducted near year's end once all theses technical pursuit tasks are completed. The following will offer a discussion of all aspects, a listing of 12 sub-tasks identified up to the point of re-entering the existing well and assigned responsibilities, and a task completion time line. The team anticipates drilling the well in mid-spring of 2004 once optimum weather conditions are prevalent in the area, pending completion of the detailed well design and the availability of specific equipment.

This document is the first of a series of progress reports for the DOE. The second will be submitted upon completion of the tasks outlined in this report.

\section{Technical Issue Discussions}

\section{Lease}

It is anticipated the current lease will be adequate for the first demonstration well. Topography in the area is difficult and it is hoped that minimal to nil earth moving will be required. The area topography will pose a problem (potential source positions) for any intended "Walk-Away VSP" survey (see VSP topic below). Both Weatherford and Imke will review/confirm with the selected rig contractor the lease layout with respect to optimum spotting of the proposed "Triple/TopDrive" drilling unit and UBD surface equipment package.

Additional on-site accommodation and a command unit will be included in the layout so that 24hour personnel coverage is maintained on site during critical well construction activity. The final lease layout will be confirmed in the final well design and consideration will be given to optimizing lease layout so that minimum alterations will be required to have all future development wells drilled from this "pad" location.

\section{Existing Well}

This well is shut in against open perforations in the target interval. A fluid level test is intended to better define the static reservoir pressure. The fact that the well has been shut in for many months provides the potential to obtain a more reliable measurement of reservoir pressure, which is critical for optimum UBD operations design. The suspended well must be plugged back to inside the $95 / 8$-in. casing at around 3400' KB for preparation of side-track. (Note: all depths will be defined as below Rotary Table/Kelly Bushing - KB.) Imke will provide confirmed rig-specific KB measurements with inclusion of rig-floor height extension for an RBOP installation above the standard BOPs (if required). Imke will ensure that all depths quoted in the well program are referenced to this rig-specific KB.

The plug-back operations will be conducted with a service rig weeks prior to mobilizing the drilling rig to give best chance for a good kick-off cement plug set. The plug will be balanced spotted through tubing and extra caution will be exercise to minimize plug distortion during removal of the tubing string. A pressure test will be conducted on the $95 / 8$-in. surface casing to 
ensure integrity and confirm pressure rating in the optional design of installing but not tying-back the 7-in. liner hung in the surface pipe.

\section{Kick-off and Curve Section}

Once rigged-in, tested, etc., the drilling rig will polish the cement plug down to design KOP (kickoff point) at around 3750' KB. The original planned trajectory included a "drop" to about $9^{\circ}$ of deviation (the original well had about $20^{\circ}$ of angle at this depth), holding that angle along a main tangent section down to a second KOP around 9500' KB. At this point a lower curve would be built at a rate of $4^{\circ} / 100^{\prime}$ to a final angle of around $80-85^{\circ}$ landing the well heel in the lower portion of the Monterey, and setting 7-in. liner at that point. A 1000' horizontal section would then be drilled holding $85^{\circ}$ to cut up through the Monterey from bottom to top along the well path from heel to toe.

This original well path plan has been adjusted as follows. The original planned employed a very conservative $4^{\circ}$ build rate for the lower curve, that may have generated considerable angled hole exposure in the problematic Sisquoc shale. To minimize shale exposure, the main $9^{\circ}$ tangent section may be drilled deeper and a more aggressive lower curve build rate (8-10\%100') will be considered to turn the well to landing angle. This would reduce shale exposure and may reduce rig time in the lower curve. Knoll will work with the directional supplier and Witter to investigate potential well trajectory options, torque and drag impacts and related BHA configurations for both curve and horizontal sections. Employment of drilling jars in the curve will also be investigated. Any future well paths would include geometry to optimize secondary leg kick-off sites and drainage line locations for option of multilateral well application.

The original plan of landing the curve in the lower portion of the Monterey target has been adjusted. The current design being considered would terminate the lower curve upon proof of top entry into the Monterey at around a $75^{\circ}$ angle. The 7 -in. liner would be cemented in place at this point, the shoe drilled out and pressure measured to confirm static pressure of the Monterey target. A short conventional core run will also be considered at this point.

This design alteration provides numerous benefits:

1. The total exposure time in the curve will be minimized to help avoid shale instability problems.

2. Monterey interval pressure testing can confirm reservoir pressure to optimize UBD operations in the horizontal section. The use and placement of a downhole deployment valve (DDV) could be finalized after the pressure test, based on optimized UBD operations requirements. This may mean running the DDV on a 7-in. tie-back from the liner hanger into the surface wellhead. All these operations would take place in a "cased hole" environment to minimize exposure time/risk in the shale sections.

3. Landing the curve in the upper Monterey will allow for more productive interval along the horizontal section, better geo-steering options (more TVD to adjust horizontal well path) and provide a relatively simple operational setting for pressure test, possible coring operations, etc.

4. Having a core recovered from the Monterey will allow for more definitive reservoir characterization, and possible investigation of drill-in fluid damage mitigation, clean-up and stimulation fluid design if necessary. Finally, having a core in the heel, and 
conventional wire-line logs from the original vertical penetration adjacent the planned toe location, gives relatively good reservoir description coverage. This along with the potential use of a gamma ray in the horizontal section BHA reduces or eliminates the need for evaluation logging runs along the horizontal section.

The curve section drilling BHA will be defined to ensure planned curve rates are well within tool capability, and that the 7-in. liner can be installed comfortably with adequate over-pull margins. Employment of drilling jars and a reaming-while-drilling (RWD) assembly will be evaluated as additional steps to ensure successful shale section conditions for running the liner. Knoll will work with Imke and the selected directional driller/rig contractor and fluids provider for all bit/BHA design in both curved and horizontal sections, torque and drag analysis, hydraulics programming, liner running and cementing, liner hanger design and installation operations, etc.

\section{Drilling Fluids}

The original plan included using a mineral oil in the curve to mitigate swelling shale. Although this approach may still be employed, it is relatively expensive, may not mitigate all shale timedependent instability, and possesses the risk of massive loss of oil if an undefined fracture is penetrated in the lower curve upon entering the Monterey formation.

The basic approach to mitigate shale instability risk will focus on minimizing exposure time in the shale section. This means no logging, testing, coring or special tool installation while the shale section is exposed. Alternate water-based fluids will be reviewed by Knoll, Imke, Weatherford to identify any lower cost options. (Note: any technical pursuits which generate alterations in the well plan will be accompanied with a cost estimate and comparison. The final well plan will include a detailed AFE to define all expected well construction costs.)

As the curve section is non-productive and will be cased, no special non-damaging attributes or processing of this drilling fluid is required. The well path is not complicated, so torque and drag should be well within operational limits of all tubulars, rig hoisting capacity, etc. The cheapest, most stable and easily disposed of fluid that allows fast, problem-free drilling of the curve is required.

\section{Horizontal Section and UBD Operations}

The adjusted plan calls for drilling out the 7 -in. shoe overbalanced with conventional fluid to cut a core and to conduct some form of reservoir pressure measurement. Upon completion of theses tasks, the UBD plan will be finalized. Weatherford will provide three separate proposals designed for low, medium and high pressure. These may include placement of a DDV in a tieback string from the 7-in. liner hanger/PBR (polished bore receptacle) to the wellhead, a modified wellhead for DDV control lines, and a stage port for using the 7-in. tieback as a "slave" string for annular gas injection.

This approach (annular gas lift) provides many benefits versus pipe injection of gas in UBD operations in this setting since the drill-in fluid could be a "non-compressive" fluid. This in turn allows for employment of conventional motors and MWD guidance and gamma ray in the horizontal section. It also minimizes pressure surges during connections and poses a safety benefit since the drill-pipe side is always full of fluid. Knoll will work with Imke and Weatherford to document a detailed program for all the UBD downhole equipment installations, UBD operations, ERP, etc. 
The basic intent will be to drill the horizontal section in a constant balanced/UBD condition. The actual UBD fluid design and operating practices required depend on drilling observations in the lower curve and reservoir pressures encountered. If a water-based system is viable, it would be given first choice since it would allow much more definitive geo-steering alternatives in the horizontal section, perhaps including gas analysis, cuttings florescence, more definitive monitoring of vented hydrocarbon volumes while drilling, etc. Extra solids-removal equipment may be employed during the horizontal section to help remove drilled fines pending fluids selection.

If gas is required, then some consideration will be placed on gas type. Air may be viable pending corrosion concerns; membrane nitrogen offers benefits but adds cost. Natural gas is not viable as there is no readily available source. These issues will be outlined and the optimum combination defined in the three-pressure-case UBD proposals.

The horizontal section well path is not dramatically altered from the original plan. The coring would generate a short tangent to be reamed out (only 10-15' of core hole is anticipated). Then $\pm 1000^{\prime}$ of $6 \frac{1}{4}$-in. open-hole horizontal section would be UBD drilled. The path would be continued at a $75-80^{\circ}$ angle to stay within the Monterey target zone along an azimuth direction thought to cross natural fractures optimally. We may consider including a gentle azimuth bend in the latter length of the horizontal section if fracture penetration is not seen to be optimum based on drilling observations.

Geosteering in the lower curve and horizontal section will include observations of ROP, cuttings description, possibly gas analysis, UBD flow from the well and gamma-ray MWD in the horizontal section. No gamma-ray is foreseen for the curve since the entry into the Monterey should be quite visible from these other observations, and the Monterey is very thick in TVD and thus appears to present a relatively easy geo-steering target to land the 7 -in. shoe.

Actual horizontal hole length drilled will depend on hole conditions experienced and in-flow observations of hydrocarbon. It is planned to use heavily gauge-protected rock bits in this section since experience with PDC's in this application has been disappointing to date. In future development well drilling, PDC's would be an obvious consideration (core data would help in this pursuit). But for this single demonstration well, there is no room for trial-and-error bit runs, thus site-specific selected insert bits are most likely. The bits would be pulled based on time of circulation on the motor and penetration rates. Each bit trip would be treated as a go/no-go decision point in respect to terminating TD at some length short of 1000'.

\section{VSP and Seismic While Drilling Pursuit}

An internal investigation conducted by Temblor has indicated that this particular operational option should be re-evaluated for employment on this first demonstration well. The local surface topography is not conducive for surface sensor placement, any special tools run on the main hole drilling assembly adds too much operational risk in the curve, the technology has not been adequately "field-proven" for application in this deep demonstration well, and there is doubt given to the value and interpretation reliability of this technology in this particular geologic/structural setting. The team believes that this particular sub-task/objective should be delayed at this point, but be considered in future development wells should that opportunity arises, and the technology be more field-proven at that time. 


\section{Production and Stimulating Options}

The team's intent is to design and construct the well as a very basic application of an horizontal well crossing multiple vertical fractures in a dual-porosity reservoir rock system. As such, the key strategy is to cross maximum fracture sets, and to avoid damaging the exposed fracture faces with drilling fluid, cuttings, cement, etc. Thus, a UBD well completed open-hole. However, this is a test well and there are many unknowns regarding structure/stratigraphy, reservoir pressure and characterization, fracture conditions, likely damaging mechanisms, etc.

The intent is to place the well on production via a tubing string ASAP after terminating drilling operations. Consideration will be given to completing the well in this manner with the drilling rig. If a DDV is installed, it may allow for a production test with the drilling rig immediately upon drilling termination. Following a successful test, the rig would be de-mobilized and the well put on permanent production.

In the event of no, or poor flow from the production test, and pending all drilling observations, a clean-up/stimulation may be considered. Again, the reservoir pressure and core recovery results and analysis will be extremely valuable in this scenario. Knoll will work with Imke and Witter to have a list of potential clean-up options for consideration should this scenario arises.

\section{Detailed Project Tasks and Time Line}

\section{Lease Layout}

Imke will generate a proposed lease layout schematic drawing including all UBD and well test equipment, personnel trailers, etc. This layout to be presented and confirmed at the final well design meeting including any additional costs related to earth moving, etc. Imke will also work with Witter et al. to generate a geologic prognosis of the planned well including expected markers, target top and bottom referenced to KB from the proposed drilling unit to be used. Completion date target: December 5, 2003.

\section{Vertical Well Plug-Back}

Imke and Witter et al. will generate an operations program and cost estimate to measure static reservoir pressure from the existing well; and to place a balanced cement plug to proposed KOP in the $95 / 8$-in. casing. Additionally, a pressure test of the $95 / 8$-in. casing is required using a service rig in the area. The reservoir pressure test should be conducted and interpreted by mid November 2003. The well should be plugged back by the end of March 2004.

\section{Basic Well Engineering}

Knoll will work with Imke and all selected contractors to assemble a basic drilling program. This will include well path and torque and drag analysis of all hole sections, any special BHA components required (e.g., jars, RWD tools, etc.).

This also includes fluid hydraulics program for the curve, additional solids removal options for the horizontal section, bit selections and drilling operating parameters for both sections. Draft program of basic engineering to be completed by December 5, 2003. 


\section{Special Operations Programming}

Knoll to work with Imke to develop special operations programming and tool selection for the possibility of cutting a short core out of the 7 -in. liner shoe and testing reservoir pressure at that point. Special ops program to be drafted by December 5, 2003.

\section{UBD Design and Equipment}

Weatherford will generate three operational UBD proposals for the horizontal section based on a low, mid and high observation of static pressure in the Monterey. These proposals will include identification and placement/operational procedures for running any special components (the DDV, slave string circulating port, modified wellhead, etc.); optimum fluid type, gas type, operating ranges of fluid and gas injection, surface equipment fluid rate and pressure operating ranges, AV requirements, and costs estimates for all three options. Knoll will work with Imke and Weatherford to generate a proposal for production testing the horizontal section with the UBD surface package and drilling rig. Basic UBD proposals and costs estimates are to be completed by December 5, 2003.

\section{Stimulation Options}

Knoll will assemble an optional proposal for clean-up/stimulation steps to be considered in case of poor inflow during production test. Proposal to be drafted after recovery of the core and completion of the reservoir pressure tests.

\section{Generate Draft Final Well Program}

Knoll will gather all components from the various team members to construct a draft Final Well Program. This document will be circulated by December 5, 2003 in preparation of a final well design team meeting.

\section{Final Well Design Team Meeting}

A team meeting including all key service providers will be conducted in Temblor offices. Targeted date is December 15, 2004. All aspects of the final design will be confirmed. Equipment and personnel requirements will be defined, operational unison of various components, and mobilization target dates confirmed.

\section{Distribute Final Well Program \& DOE Status Report}

Based on all decisions and input from the team meeting, the program document will be finalized and an interim progress report drafted for Management review and subsequently presented to DOE. Status report draft to be completed by January 25, 2004.

\section{Pre-spud Meeting, Safety Orientation}

Once the drilling rig package mobilization is initiated, all rig personnel, key service providers and team members will meet in a Los Alamos location to conduct a pre-spud safety orientation meeting. All project goals and assumptions will be reviewed/confirmed, all operational steps and contingencies outlined, operational authority and Emergency Response Plan (ERP) will be detailed. Pre-spud meeting date is targeted near April 15, 2004 pending equipment availability and weather conditions. 


\section{Temblor-Los Alamos DOE Demonstration Project Meeting Notes (2) Bakersfield, CA - January 21, 2004}

\section{Summary}

A full team meeting held January 21, 2004 in Bakersfield was very successful in finalizing all major aspects of well construction. All information is now assembled to begin documenting a formal well construction program and AFE. MTI (Bob Knoll) and Temblor, Harold Imke, Imke, will now document the AFE and plan to have the finalized version for distribution/approval by mid February 2004. In February some critical consumables, (e.g.; casing, well-head, liner hanger/DPV etc.) must be formally ordered by Temblor for a targeted spud date of early May 2004. Knoll is responsible to work with the directional drilling providers and Weatherford on a final well trajectory plan, and then conduct analysis on T\&D, hydraulics etc. All this to be incorporated into the well program document targeted for draft distribution by late March 2004. A pre-spud meeting would then be scheduled for immediately prior to field operations, tentatively targeted the first week of May 2004.

\section{Final Well Design Highlights}

The major well design elements altered or finalized during the team meeting are summarized as follows:

$>$ Surface lease should be OK as is with little expansion required. The rig people will probably be housed in nearby hotels/motels. Imke will confirm total number of accommodation/support trailers on site, and will coordinate with rig provider, Weatherford and all other services to generate a planned plot view of lease lay-out, confirm water source etc.

$>$ The new surface casing option will be pursued. Temblor to pursue/confirm all well permitting issues. The new surface hole will use a more conventional grade 10.75-in. casing since the 7-in. liner will be tied back upon completion as the primary production casing string. The original well will be pumped in the interim, but production operations would be suspended on this well during construction of the new well.

$>$ The main hole $(95 / 8$-in. bit to drill vertical and curve to 7 -in. liner landing point at about an $80^{\circ}$ angle and 10,000' TVD) trajectory has been modified based on most likely problematic shale exposure in the curved section. Both the team geologist and geophysicist will review structure/lithology to update well prognosis with anticipated critical hole sections and lithological tops. The new path option includes hitting a "heal target" defined by seismic as a potential highly fractured sweet spot. The G\&G team members must consider this new target option - would it represent a hole trouble risk?, and if so should the well path attempt to avoid it? Based on this review, Knoll will finalize well trajectory with Imke and the directional suppliers, and finalize T\&D, hydraulics program etc. based on the final planned well path. 
$>$ The main hole will be drilled with performance motors, larger hole ( $97 / 8$-in.) and with water based mud. The fluid system will be weighted and may include inhibiting salts/additives. This section may incorporate a slight negative angle in the upper portion below surface casing to allow optimal lower KOP and build rate in lower curve, and lateral space to hit the new heal target option if this possible "sweet spot" does not pose a hole trouble risk. Mud logging, cuttings analysis, and penetration rate will be the primary geosteering indicators to observe entry into the high resistivity Monterey and to pick 7-in. casing point.

$>$ The coring option below the 7-in. liner shoe will be held as a contingency only, plans and costs will be included in the program/AFE as a contingency. UBD plans have been finalized and simplified. The 7-in. slave string will be tied back to the main wellhead via a PBR assembly in the 7-in. hanger. This tied-back string will have a port sub below the deployment valve (DPV) and above the PBR seal. This will provide a secured flow path for air injection to gas lift the 7-in. slave string by drill string annulus.

$>$ All out-flow in the UBD section will be diverted through a choke manifold into a large atmospheric separator (gas buster); underflow from this vessel will be fed to either dedicated oil skimming tanks and/or the rigs inflow system for solids removal and return of base water to the rig pits. The mud loggers will coordinate through Knoll/lmke regarding set up of sample catchers, gas probe location etc. Knoll/Imke will coordinate with rig provider, fluids supplier, Weatherford and waste management provider to generate a surface equipment lay-out, and fluids flow/handling plan/schematic, and BOP stack-up drawing to fit under the rig floor.

$>$ BHP will be monitored by an LWD pressure monitor on the BHA, no other LWD sensors are planned for the productive interval. No other evaluation logging is planned for the productive interval. Final TD will be called on site based on hydrocarbon inflow observations, hole length, conditions and cuttings analysis. Fresh water will be the preferred drill-in fluid, with additions of viscosifiers if hole cleaning dictates their use. Once TD is called, this section will be sealed by packers, the DPV recovered and the 7 in. tied back to the wellhead as a standard production casing. The well would then be completed with a tubing string tail pipe, packer, and pump setting nipple assembly. Weatherford will submit a detailed completions plan and cost quote for Imke and Knoll to finalize well program/AFE. 


\section{Team Meeting Notes (3)}

\section{Productive Interval Construction \& Completion Objectives, Well Design Modifications and Operational Constraints Guidelines}

\section{Introduction}

To date (November 12, 2004), 7-in. casing point at 10,245 MD, the vertical/upper curved portion of the well has been constructed according to base plan. The high-resistivity Monterey appears from all indications to have been encountered as predicted at a measured depth of 10,200' (10,000'TVD). At $\pm 10,228$ ' a very strong oil fracture crossing was indicated by oil/gas shows, mineralogy and bit response. The base plan to drill the lower 9.825-in. curve to the lower-mid Monterey landing target @ 80 inclination was modified and the 7-in. casing point called at this current depth since:

1. Delays in the main hole section have led to open-hole exposure time approaching the perceived maximum allowable time in problematic shales; the first priority in this section is to successfully case off the shales into the Monterey. The team is highly confident the high-resistivity Monterey has been reached, and thus feel it prudent to case the exposed upper shales before they become a concern.

2. The immediate crossing of an oil fracture upon entering the Monterey is very encouraging. The fracture will likely contribute to production if left uncased. The team feels it's best to set casing at the top of the Monterey, maintaining exposure to this fracture in the 6.25' open horizontal productive interval. The strong nature of the siliceous rich Monterey suggests that very little hole stability risk is posed by leaving this fracture uncased directly (e.g., 20-40') below the 7-in. liner shoe, and this (open-hole completion) setting is deemed safe for all the horizontal section productive interval within the Monterey member.

3. Both milled tooth and insert bit runs in the upper Monterey shale resulted in disappointing penetration rates; however, a PDC run in this section into the Monterey delivered good penetration rate. The well-site management team, is encouraged by this PDC performance to the point of intending a PDC run in the lower curve/horizontal interval in the smaller hole size. It is felt that the remaining lower curve (e.g.; from $60^{\circ}$ to $80^{\circ}$ inclination) can be more effectively constructed in the smaller hole size in a MPD mode versus the current larger hole size in an over-balanced mode.

This slight alteration in the base plan impacts the lower curve construction, and the early penetration of a good oil fracture amplifies the hope that many more may be accessed in the horizontal section. The most difficult aspect of the well has now been successfully drilled and cased; but the most novel and dynamic operations are approaching. There are many unknowns regarding the reservoir characteristics. This particular asset setting and the productive interval MPD construction/completion intended methodology involves many novel aspects for all concerned. Many of these issues and operational methodologies will be outside the standard practice of the drilling crews, supervisors, etc. There is no standard program or line to follow. Thus dynamic alterations to operational parameters will be required during all the MPD well 
construction/completion. In preparation for this, it is necessary to have all field staff involved in a pre-drill-out orientation/safety meeting to:

1. Confirm field operations chain-of-command. Reconfirm base well objectives and establish operational constraints and limit guidelines for the remainder of the well construction/completion activities.

2. Examine and address any operational aspects affected by the change in lower curve design and setting 7-in. shoe at the top of the Monterey.

3. Walk through all the remaining procedures, equipment and service requirements from installing DPV/MPD systems to placing the well on production with a service rig.

This memo hopes to provide the well-site management team with some background and draft constraint guidelines to be reviewed/edited and approved by the team, then utilized at the predrill-out well-site meeting for all crew members. Any and all additional points/comments provided by any of the service providers, and approved by the well-site management team should also be voiced and reviewed at this up-coming meeting.

\section{Background Review}

\section{What is the High-Resistivity Monterey?}

It is a very hard, highly siliceous and very finely bedded Miocene shale formation. It is the source rock for all Monterey production in the area. There is very little data regarding reservoir characterization, and there is no production data in this particular structure, which is very deeply placed (3000-4000' deeper) relative to all Monterey fields in the area. We do know that two previous penetrations into this Monterey structure (both approximately 1200' northwest of the current well's bottom hole location) encountered at least 500' of oil column with no top gas or bottom water. Neither well will produce at an economic rate, even after extensive stimulation/clean-up attempts. The rock is very tight $(0.001 \mathrm{mD})$, and the proximity of the previous wells to natural fractures is unknown, but indications suggest that vertical fractures exist, and the matrix may also have micro-fractures. Seismic anomalies may indicate more highly fractured material in close proximity to the previous two wells, and also a second general area near the original end-of-curve target of the existing well. The fact that we crossed one fracture set already in only $45^{\prime}$ of Monterey penetration at a $60^{\circ}$ inclination is very promising.

\section{What is Base Objective of the Well?}

The primary goal is to place \pm 2100 ' of open-hole horizontal interval in the oil column of the Monterey. To construct and complete this section using MPD practices and the DDV (downhole deployment valve) system to always maintain the productive interval in a near-balanced condition with non-damaging fluids, and to put that interval on production immediately after drilling. The well is orientated to cross fractures normal to their anticipated orientation. The lower curve and horizontal section is designed to build and hold an inclination of approximately $80^{\circ}$ to cross through the lower, mid and upper Monterey along well length as it approaches the bottom hole locations of the two previous wells in a down-dip structure direction.

There are many reservoir unknowns. Our best guess is that each successfully penetrated and undamaged fracture set may contribute around 50 BOPD; and these sets may be occurring 
around every 100' of along-hole length. Thus, 2000' would access \pm 20 fracture sets and deliver around 1000 BOPD.

This Monterey structure looks to be well defined by seismic, as confirmed by the two previous wells, in addition to the current well experiencing the Monterey top almost exactly on prognosis. It is very thick, and has no bottom-water or top-gas risk, so fine control of planned versus actual well inclination and Azimuth along the productive length should not be a major concern or constraint. The vertical fractures are thought to extend through the Monterey oil column, so being a little low or high in the general target is not seen as a major concern.

\section{What are the Key Unknowns?}

The most critical unknown is static reservoir pressure. This dictates that MPD operations must be flexible to respond to this variable. The highest conceivable reservoir pressure is thought to be around 5200 psi (e.g., basically normally pressured), although more detailed investigations recently conducted could be interpreted to indicate much lower reservoir pressure (e.g., between 4600 and 4800 psi).

The dual-porosity nature of this play, coupled with the unknowns of fracture density, conductivity and the recharge ability of the tight matrix all conspire to make any accurate prediction of inflow dynamics and rapid pressure decline behavior tenuous, at best. The water base drill-in fluid would likely provide a near-balanced BHP regime without air injection if the fractures are at the maximum perceived pressure. Given the well defined and relatively small closure on the structure, any one single fracture set in-flow would likely exhibit rapid decline. The key will be to access many fracture sets in a non-damaging, near-balanced mode. The length goal (2100') depends on the number of fracture sets encountered, the existing MPD parameters and hole conditions, etc.; thus, extending beyond or terminating short of this length may be desired/required as well behavior dictates. Longer is better, but the system has limits and safety must have top priority.

\section{Suggested MPD Limits and Constraints}

This is not intended to be a flow-drilling or UBD operation. MPD is employed to maintain a near-balanced condition so that fracture crossing can be observed by gas cut or oil in-flow variance, monitored BHP variance, etc., and significant oil in-flow is curtailed without damaging same. The hydrocarbon inflow and surface pressure must be kept at a minimum so as not to tax the surface systems fluid handling capability. As more non-damaged fracture sets are exposed, one might expect more drilled oil and gas evolution; and, thus, perhaps increasing oil flow and back-pressure requirements at surface. There has been no production from this structure; reservoir pressure should be evenly distributed between the fracture sets.

Safety is the first priority. If at any time the rates or pressure are seen to be excessive, drilling operations should be terminated. This is where the field experience of the Weatherford on-site supervisor and the rest of the well-site management team must be applied. The at-start guidelines and constraints must be established by the on-site well-site management team and adjusted as well response dictates. The existing exposure of the first good fracture below the 7in. liner shoe should provide some valuable observations in this regard. Once the shoe is drilled-out and rat-hole cleaned, adjustments to MPD parameters can be conducted that may help to define the fracture pressure, in-flow and recharge behavior. This should help target the best MPD constraints for going forward in the horizontal section. 
As a suggested starting point, the following points are offered:

> MPD air/fluid rate are designed to achieve the targeted near-balanced condition with minimal surface pressure (around 50-100 psi), assuming a rechargeable fracture pressure of approximately 4600 psi. A maximum sustained surface pressure limit might be around 750 psi. If this level of back pressure is required with no air injection, consideration might be given to terminating drilling at that point.

> Allowing for a minimal inflow while drilling from each fracture set of 10 BOPD, and assuming sets are 100' spaced, the maximum oil inflow might be constrained to 100 BOPD per 1000' $\mathrm{ft}$ of length. If this rate is observed without air injection, consideration should be given to stop drilling. Clearly this constraint would need adjustments as fracture crossing is observed.

\section{Suggested Agenda Topics for the Pre-drill-out On-Site Meeting:}

Weatherford will conduct a full operations/safety orientation meeting prior to starting MPD operations. This will include a full review of slave string placement and recovery, as well as tripping procedures and DPV operations. Once the well-site management team reviews, modifies and establishes the MPD constraints, the orientation meeting should also offer:

1. Background of setting and basic objectives review. Chain-of-command, preliminary operating constraints, etc.

2. Emergency response plan and kill procedures, kill fluid design and placement procedures.

3. Bit/BHA design for drill out, initial MPD function test and initial parameter setting, etc. (air/fluid rates, back pressure, flare and production rates, etc.).

4. Method of TD determination.

5. A detailed well suspension, tie-back and putting-on-production program review.

6. Any other topics raised. 


\section{Appendix B}

\section{Drilling Program \\ Version 3.1 \\ For Well}

Castillo, Ross and Howe 2-19 


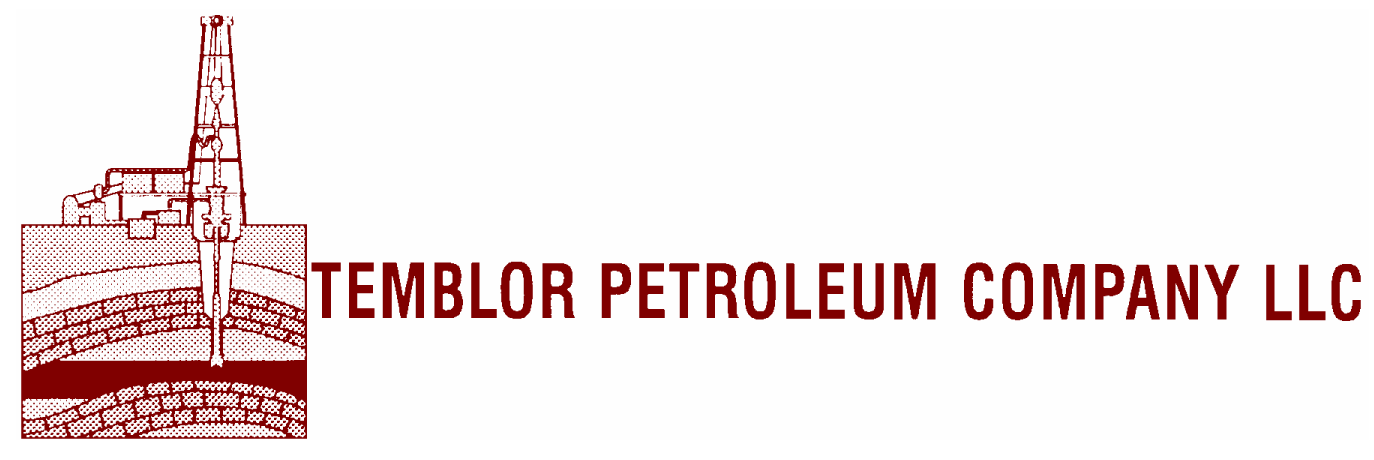

DRILLING PROGRAM

Version 3.1

Well

Castillo, Ross and Howe 2-19

Location: SEC 19: T8N: R32W: SB B\&M.

Santa Barbara County

Date: August 16, 2004

Prepared by: H. Imke

Note:

This program is intended as a guide. Actual operating and well conditions may necessitate a departure from the program in the interests of safety, wellbore integrity and prudent drilling practices. 


\section{General Information}

WELL NAME:

SURFACE LOCATION:

WELL TYPE:

AFE \#:

API \#:

D.O.G Permit No:

ELEVATIONS:

DRILLING RIG:

PROPOSED TD:

OBJECTIVE:

CORES:

DST's:

MUD SYSTEM:

$\mathrm{H}_{2}$ S REQUIREMENTS:

CLASSIFICATION:
Castillo 2-19

Sec. 19: T8N: R32W: SB B\&M

Zone 5, CSPCS, NAD27, \& NGVD29

N 464741.3: E1313405.1

Lat: $34^{\circ} 45^{\prime} 22.191^{\prime \prime} \mathrm{N}$

Long: $120^{\circ} 17^{\prime} 38.518^{\prime \prime} \mathrm{W}$

Oil \& Gas

083-22388

P 304-134

632.4' MSL

Nabors \# 473

12,550' \pm RT-MD (est. 39 days)

Monterey Shale

None

None

Water Based

Monitors

Development - Confidential - "Tight Hole" 


\section{PROGRAM SUMMARY}

1. Make cellar, set 20" conductor at 70', dig rat hole and mouse hole and move-in Nabors Rig 473.

2. Drill 14 3/4" surface hole to 3500' RT minimum.

3. Run $103 / 4$ " casing and cement to surface.

4. Install $11 " \times 103 / 4 " \times 5000$ psi casing bowl designed for deployment valve set up. Install and test Class III 5M BOPE and casing. Drill out and perform a leak off test.

5. Drill 9 7/8" with a straight hole mud motor to approximately 9250' RT.

6. Directional drill remainder of the $97 / 8$ " hole to 80 degrees, to a TVD of $\pm 10,082$ ' and MD of $\pm 10,444$.

7. Run 7" casing and hang in the $103 / 4^{\prime \prime}$ casing at \pm 3300 '. Cement back to 7500 '. Cement must be 500' above any productive zone. Test the liner hanger seal to $2500 \mathrm{psi}$.

8. Run 7" casing 'slave' string with ported sub/check valves and Weatherford 'deployment valve' to the top of the 7 " hanger at \pm 3300 '. Test the internal seal of the 7 " slave string to 2500 psi. Perform a full function and pressure test of the entire under-balanced system.

9. Drill a $61 / 8$ " under-balanced hole horizontal approximately 1000', TVD-10,450' \pm , MD 12,550 ' \pm .

10. Run a permanent packer in the 7" casing. Pull the 7" slave string with ported sub/check valves and Weatherford 'deployment valve'.

11. Run the 7" tie back string to surface and test the tie back to 2500 psi.

12. Rig down and move out Nabors "Rig 473".

13. Move in and rig up a production rig and pick up and test $27 / 8$ " tubing running in the hole and tie into the packer.

14. Rig up a slick line. Pull the packer plug and put the well on production.

\section{MUD PROGRAM}

Surface: Gel Chem. Adjust viscosity to clean the hole as required.

Intermediate: Gel Chem. Cypan (sodium polyacrylate) neutral-medium pH mud system

Production Formation: Water. Maintain $8-9 \mathrm{pH}$

\section{CASING \& CEMENTING DESIGN}

Surface:

Minimum Casing: $\quad 0-3500^{\prime}$ RT, 10 3/4"; 45.50 lb/ft; K-55; BTC. 


\author{
9 7/8" drift (14 3/4" hole size). \\ Cement: Cement from 3500' RT to surface as per program. \\ Cement volume is to be calculated on the basis of gauge hole $+25 \%$ - \\ $35 \%$ excess. Add LCM to slurry if losses are experienced while drilling.
}

\title{
PRODUCTION CASING:
}

Minimum Casing:

Cement:
3300-10,500 \pm RT: 7", 26\#; P110; HC Butt., N-80 ; 26\# ; LT\&C. (9 7/8" hole size)

Cement from 10,500' RT to 7500'.

Cement volume is to be calculated $+15 \%$.

\section{HOLE PROBLEM CONSIDERATIONS}

\section{Lost Circulation:}

The closest offsets had no lost circulation while drilling surface hole. Have some lost circulation material on location. The $97 / 8$ " section is not noted for lost circulation.

Significant hole sloughing, swelling and running shale have been experienced on offsets wells in the $97 / 8$ " section in the Sisquoc. Increasing the mud weight and/or adding Soltex as indications dictate should control any problems. This area is also bad for key seating.

\section{Deviation:}

Deviation can be a problem in this area. Watch deviation closely and make corrections with drilling parameters. We want to drill the surface hole and the $97 / 8$ " hole down to the KOP straight. The $97 / 8$ " hole will be drilled with a straight hole mud motor and MWD.

\section{Abnormal pressure:}

Precautions should always be taken in case of abnormal pressure. Offsets do not show any significant pressure issues different than the mud wts. that are programmed for this well to TD. Ensure crew are informed and well is flow checked on penetration of these zones. Drilling supervisor to be on the floor when penetrating these zones and all other objective zones.

\section{Tight hole/Reaming:}

Tight hole conditions are generally observed at different intervals through out the well. Wipe the hole as needed and keep the mud in good condition. There are many shale intervals to TD which are water sensitive and/or overpressured. Minimize mechanical disturbance by controlling trip speeds to $30-60 \mathrm{sec} . / \mathrm{std}$. as the hole conditions warrant. Work connections to ensure that packing around the drill string does not lead to pressuring up on the hole. 


\title{
GENERAL RESPONSIBILITIES
}

1. E-mail morning reports by 8:00 AM to drilling manager and team leader. Call in each morning to the drilling manager or his designee

2. Notify the D.O.G.G.R. field office (See permit) within $24 \mathrm{hrs}$ of spudding the well. Notify this office of lost returns on surface hole and if cement returns are not obtained at surface. 'Tour sheets' are to be properly filled out and sent to the Bakersfield office at the completion of the well.

3. Drilling Supervisor is to be familiar with and enforce regulations as they pertain to work at the site.

4. Confirm that the lease is properly prepared. Have all garbage and metal removed from the lease after drilling and contained in proper recycling/disposal bin. Ensure mousehole and rathole are covered immediately after rig demobilization.

5. The Drilling Supervisor is to hold a prespud meeting $w /$ crews on location and record in tour book. Weekly meetings are to be held thereafter. The drilling supervisor is to confirm that the rig crews are trained in the operation of BOP's and that all drillers have a valid first line supervisor's BOP certificate.

6. The Drilling Supervisor is to ensure the hole is properly filled on trips and trip records are properly completed. Ensure that BOP's and accumulator are all satisfactory prior to drilling out. Conduct BOP drills at drillout and at least weekly thereafter. Conduct flow checks as per D.O.G.G.R. regulations. Log all BOP drills in the IADC log book.

7. The GL (632.4') and RT (19' 3") elevation and location (are to be noted on the first report.

8. All field tickets are to be coded and signed by the drilling supervisor and forwarded to the Bakersfield office on a weekly basis. Any discrepancies are to be brought to the attention of the drilling manager. The AFE number and well name must be recorded on all field tickets.

\section{GEOLOGIC PROGNOSIS}

\author{
Projected Formation Tops
}

Sisquoc - 5660'

MontereyShale ----9600' 


\section{DRILLING PROGRAM}

\section{SURFACE HOLE: $14 \% 34^{\prime \prime}-3500$ ' RT}

1. Hold a pre-spud meeting with tool pusher, crew and drilling fluid company representative.

2. Pick up a pendulum string of 8" drill collars. BHA should be discussed with drilling manager prior to picking up.

3. Spud in with gel mud and drill a $143 / 4$ " hole to $10 \mathrm{ft}$ below surface casing setting depth. Ensure pump rate and rotary speed are minimized while drilling through bottom of conductor.

4. Keep the mud weight to a minimum and adjust the viscosity as required to clean the hole. Work the pipe on connections to minimize the risk of mud rings.

5. "Single-shot" survey every 300'. Expand survey interval depending on deviation. Maximum allowable deviation desired is $2^{\circ}$. Discuss surveys and drilling parameters with drilling manager.

6. At surface pipe TD, wipe the hole to the conductor shoe and "strap" the drill string out of the hole. If an incompetent formation is encountered at the casing setting depth, deepen the hole to ensure that the shoe is set at least 30 ' into a competent formation.

7. Condition mud and hole prior to running casing. If gravel or lost circulation was a problem while drilling, it may be necessary to raise the viscosity.

8. Tally, visually inspect and run casing as per Casing and Cementing section.

9. Wait on cement a minimum of four hours. Check cement samples before slacking off.

10. Cut off the casing and weld on an 11" $\times 9$ 5/8" $\times 5000 p s i$ (SOW) casing head complete with wear bushing, side outlets and gate valves. Pressure test the weld to 1000 psi for 15 minutes. Note the type of bowl, serial number and pressure rating on tour sheets and morning report. Ensure the casing head is on straight.

11. Install the BOP stack. Pressure test BOP's, 10-3/4" casing and manifold to 200psi and 2500psi for 10 minutes. Run an open-ended test plug and test the BOP and manifold to 5000psi as per Well Control section. All BOPE must be as defined by the D.O.G.G.R. manual MO 7, DOG Class III, 5M with hole fluid monitoring equipment ' $\mathrm{B}$ '.

- $\quad$ All pressure tests are to be witnessed and approved by the drilling supervisor and the D.O.G.G.R. as required.

12. Complete the rig inspection and well control sheets (post sheets in the doghouse). All serious deficiencies must be remedied prior to drill out. Note deficiencies and actions taken on morning report. 


\section{INTERMEDIATE HOLE: 97/8" - 10,500' RT (TD)}

1. Clean out the insert, cement, shoe and drill 10' of new hole and perform a leak-off test. Immediately report leak-off test results to drilling manager. Drill ahead with the $97 / 8$ " hole using a performance mud motor and MWD to the determined KOP then pick up a 2 degree motor and drill the curve section to $10,500 \pm$.

2. At total depth, circulate and condition mud, $\mathrm{POOH}$ and make up a bull nosed hole opener and a 3-point reamer, ream the curve section carefully and back circulate every 300' in the curve section. Ensure the hole is conditioned as per program and in consultation with the drilling manager.

3. Run the 7" casing as per the casing and cement program.

4. Test the liner hanger/packer to 2500 psi.

5. Run a 7" slave string with subs with either check valves or gas-lift type mandrels and the 'Weatherford' down-hole deployment valve. Land-out in the $103 / 4$ " casing bowl. Test the slave string internally to $2500 \mathrm{psi}$.

6. Re-test the BOP stack if required by the D.O.G.G.R.

7. Nipple up the "Williams 7000" rotating head and all of Weatherford's under-balanced equipment. Perform a full function test of the entire under-balanced system. Notify the D.O.G.G.R. of the test so that they may witness if desired.

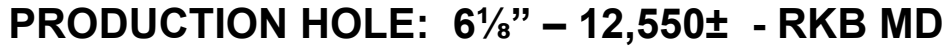

1. Clean out the plug, cement, shoe and directionally drill the horizontal section (1000' \pm ) with a Mud Motor, MWD and down hole pressure sub.

2. Run a Weatherford permanent packer assembly and set in the 7" casing.

3. Pull the 7" casing slave string and run a 7" tie back string. Test the tie back to 2500 psi.

4. Rig down and move out Nabors Rig 473.

5. Move in a production rig. Run 2 7/8" tubing and retrieve the plug out of the permanent packer assembly and put the well on production. 


\section{WELL CONTROL}

(1) Minimum BOP stack layout and manifold system are as per D.O.G.G.R. regulations. Ensure flare line is staked or adequately weighted down.

(2) Drill string blow-out prevention peripheral equipment needed:

- drill pipe inside BOP with removable handles

- drill pipe stabbing valve with removable handles (in open position)

- upper and lower kelly cocks (with wrenches)

(3) Test the annular preventer, the HCR valve, and all rams by cycling each item from both the rig floor and remote control stations and verify full and correct function of every item..

(4) Test the accumulator operation by:

(a) Fully opening the annular preventer and rams.

(b) Charging the accumulator to full working pressure then disconnecting the charge pump.

(c) Opening the HCR valve and fully closing the annular preventer. Checking that closure was within 60 seconds and that accumulator pressure remains above 1200 psi.

(d) Reconnecting the charge pump and checking that full working pressure is recovered within 5 minutes.

(e) Closing each set of rams in turn and checking that closing time is less than 30 seconds (from full accumulator working pressure and with the charge pump disabled).

(5) Check that each nitrogen bottle is charged to at least 1800 psi.

(6) Pressure test the BOP system with water. Each test to last 10 minutes at 200 psi then 10 minutes at 5000 psi.

(a) Flush the system of all mud prior to testing.

(b) Any indication of leakage or a pressure loss of more than $10 \%$ of the test pressure over a 10-minute period is a failure that requires corrective action (This assumes a test plug is not in place).

(c) Pressure is to be applied in the same direction that a kick would pressurize the item being tested.

(d) All valves downstream of the item being tested are to be open. Pressure test the kill line and each valve on that line by increasing pressure upstream of the check valve.

be

(e) If any test pressure exceeds $67 \%$ of casing burst pressure a hanger test plug must used.

(f) The following must be recorded in the tour book:

- BOP tested

- Test duration

- Test pressure observed at the start and finish of each test.

Test: a) each ram

b) The annular preventer against drill pipe (1500 psi high)

c) Each valve on the drilling spool

d) Each valve and choke in the manifold

e) The drill string inside BOP

f) The drill string stabbing valve

g) The kelly cocks

h) The kill line

i) Surface casing 
(7) ALL FLANGES AND FITTINGS THROUGHOUT THE BOP SYSTEM (STACK, MANIFOLD AND ASSOCIATED LINES) ARE TO BE RE-TIGHTENED AFTER ONE DAY OF DRILLING.

(8) Air shut-offs on all diesel motors to be tested prior to drill out and every week thereafter.

(9) Record all the above checks and tests in addition to those listed below with results on "Daily Drilling Report". The following check should be completed as detailed below:

a) Daily:

(i) Measure standpipe pressure at the well-kill pump speed and update the Kick Control Worksheet. Post Kick Control Sheet in doghouse and manifold shack upon completion.

(ii) Close and open a set of pipe rams or the annular preventer (each tour, alternate floor controls with remotes).

(iii) Close and open the blind rams after each trip out of hole.

b) At Least Weekly:

(i) Driller's engine shut-offs are to be tested.

(ii) A blow out prevention drill is to be held with each crew.

(iii) Tighten BOP bolts

c) (i) Complete a Trip Worksheet for each trip and keep on record to end of hole.

(ii) Keep hole full at all times.

(10) Kick Control Worksheet to be posted in the doghouse.

(11) Drillers must hold current well control certificates. Record drillers names and dates of last certification.

(12) All rig crews to be trained in operating the BOP equipment and a rig blowout prevention drill held for each crew prior to drill out.

(13) Drillstring pressure gauge at the choke manifold must to be hooked up and working at all times.

(14) All mud level indicators, flow indicators and alarm settings are to be checked daily. Any malfunction is to be corrected immediately. PVT must alarm at $+/-5.0$ bbls and the flow show must alarm at $+/-10 \%$ of measured flow.

(15) The Driller's Method (constant drillpipe pressure) is to be used to control a kick. If the shut in casing pressure exceeds the posted MACP, the Low Choke Method is to be used. 


\section{MUD PROGRAM}

Interval Type Density Viscosity WL $\quad$ Remarks

0-3500' Gel_Water Min. $\quad 50-80 \quad 12-15 \mathrm{cc} \quad$ Operate all solids equipment.

3500-10,500-Gel-Cypan 9-11.0ppg 38-44 4-6 cc

10,500-12,550-Water 8.33ppg Maintain a 8-9 pH

Maintain the Mud Wt. as the hole conditions dictate.

Operate the solids equipment as per the Mud Engineer. 


\section{CASING AND CEMENTING}

$103 / 4$ " SURFACE CASING

\section{Surface Casing Design}

\begin{tabular}{|c|c|c||}
\hline \hline INTERVAL & LENGTH & DESCRIPTION \\
\hline $0-3500 \mathrm{ft}$ & $3500 \mathrm{ft}$ & $103 / 4 ", 45.50 \mathrm{lb} / \mathrm{ft}, \mathrm{N}-80, \mathrm{BTC}$ \\
\hline
\end{tabular}

\section{Minimum Performance Properties:}

$\begin{array}{ll}\text { ID: } & 9.950 " \\ \text { Drift: } & 9.875 " \\ \text { Burst: } & 3580 \text { PSI } \\ \text { Collapse: } & 2090 \text { PSI } \\ \text { Joint Strength: } & 931 \\ \text { Body: } & 1236 \\ \text { Optimum Torque (Ft-lbs.) } & \text { (Buttress) }\end{array}$

1. Run surface casing in the hole as follows:

(a) $103 / 4$ " float shoe (thread-locked)-PDC drillable

(b) One joint of $103 / 4$ " casing (casing collar to be thread-locked)

(c) $103 / 4$ " float collar- PDC drillable

(d) One joint $103 / 4$ " casing (casing collar to be thread-locked)

(e) $\quad 103 / 4$ " casing to $3500 \mathrm{ft}$ (ensure casing is doped with API Modified)

2. Arrange for power tong services.

3. Visually inspect the surface casing for signs of transport damage, clean and inspect threads.

4. Strap casing on rack.

5. Place clean thread protectors on the pin end of the pipe to protect the threads from handling damage between the pipe racks and rig floor. Several thread protectors should be cleaned and used for this purpose or use quickie protectors if they will work.

6. Assemble the guide shoe, shoe joint and insert valve, applying thread-lock to thread ends.

7. Make up and run the $103 / 4$ " casing as per buttress specifications. Apply thread compound over entire surface of threads before stabbing.

8. When stabbing, lower casing slowly to avoid damaging threads. Stab vertically with the assistance of a man on the stabbing board. Rotate slowly to ensure proper thread engagement. If any threads are damaged while stabbing, lift up, clean the threads and repair damage if possible with a 3 point file. Clean filings and re-apply thread compound. 
9. Centralizers to be placed as follows:

$1-6 \mathrm{ft}$ above guide shoe

$1-1^{\text {st }}$. collar

1 - on each of the next two casing collars uphole

- remaining centralizers every $3^{\text {rd }}$. collar to surface.

10. Pick up and lower casing string carefully. Running time should not exceed 25 secs/joint. Check to make sure that the casing is filling as you are running it in the hole.

11. When landing the casing, ensure that the top of the last joint is close to the table. Drill the surface hole to fit the casing.

12. Install cementing head on last joint and circulate to TD. After casing is landed, circulate and condition the mud.

13. Reciprocate the casing in short strokes until the pipe is free, then increase stroke length to $15-20 \mathrm{ft}$. Circulate the hole clean, reduce viscosity, gel strengths and yield point, if possible, for cementing. Circulate until returns are clean, or a minimum of two full circulations.

NOTE: Ensure that rig hands clear the V-door area completely and move to the rear area of the catwalk as tubulars are being hoisted from the cat-walk and into the derrick!

\section{Surface Casing Cementing:}

Casing is to be cemented from total depth to surface with type III cement plus additives as per program. Ensure a cementing head and rubber plug is used. Cement volumes are calculated based on gauge hole plus $25 \%$ - $35 \%$ excess and an interval length of $3500 \mathrm{ft}$. If circulation was lost while drilling, ensure an adequate amount of LCM is mixed with the cement. If total losses occur while drilling, be prepared to use a 'spaghetti' string to top up cement in the annulus.

1. Cement the casing as follows:

(a) Install plug loading cement head complete with top plug. (Supervisor to witness plug being loaded) Pump 15 bbl water spacer. Pressure test treating lines to 2000 psi.

(b) Mix and pump Halliburton light Premium plus with 1\% Calcium chloride, .05\% FWCA, .5\% Halad 322 mixed with fresh water to 13.50 ppg. Tail 500' of Premium Plus with $1 \%$ calcium chloride mixed with fresh water to $14.8 \mathrm{ppg}$. Mix at 5 to $6.0 \mathrm{bpm}$.

(c) Release the top plug and displace cement with mud at a rate of at least $6.0 \mathrm{bpm}$. Final volumes to be determined on location in consultation with the cement company engineer. Decrease the displacement rate on the last $10 \mathrm{bbl}$ If lost circulation occurs, stage in last $10 \mathrm{bbl}$ of displacement.

(d) Bump plug to 500psi over pumping pressure. Release pressure and check for back-flow. If float does not hold, shut-in and hold back pressure for four hours. Release pressure in increments to avoid creating a micro-annulus. If plug does not bump on 
theoretical displacement, do not overdisplace by more than two thirds of the shoe joint volume.

(e) Centralize casing in the rotary table. Do not cut-off landing joint sooner than four hours after bumping plug.

\section{7"' INTERMEDIATE CASING}

\section{Casing Design}

\begin{tabular}{||l||l|l||}
\hline Casing Interval & Length & Description \\
\hline $3300-10500 \mathrm{ft}$ & $7200 \mathrm{ft}$ & $7{ }^{\prime \prime}, 26 \mathrm{lb} / \mathrm{ft}, \mathrm{P} 110 \mathrm{HC}$ Butt, N-80, LTC, SMSL \\
\hline \hline P-110 Butt. On bottom & 1500 ' & \\
\hline
\end{tabular}

\section{Casing Properties}

\begin{tabular}{|l|l|l|}
\hline & 7", $26 \mathrm{lb} / \mathrm{ft}, \mathrm{HC}-\mathrm{P} 110$, BTC & 7", 26\#, N-80 LTC \\
\hline I.D. (in): & 6.276 & 6.276 \\
\hline Drift (in): & 6.151 & 6.151 \\
\hline Burst (psi): & 11.220 & 7240 \\
\hline Collapse (psi): & 6210 & 5410 \\
\hline Joint Strength (1000lbs): & 853 & 519 \\
\hline Optimum Torque (Ft-lbs): & & 3640 \\
\hline Min Torque (Ft-lbs): & & 2730 \\
\hline Max Torque (Ft-lbs): & & 4550 \\
\hline & & \\
\hline
\end{tabular}

1. Run casing in the hole as follows:

(Buttress threads are to be run from TD back through the transition "curve")

(a) 7" float shoe

(b) Two joints 7" casing

(c) 7 " float collar.

(d) Install Two centralizers on the first four joints. One at 15' and on the collar or with a stop collar if necessary. Run centralizers on every collar from the first four joints through the entire curve. Then 1 every third joint to 7000'. Use semirigid centralizers.

2. Visually inspect the intermediate casing for signs of transport damage. Clean and inspect threads and re-drift casing.

3. Strap casing on the rack. 
4. Place clean thread protectors on the pin end of the pipe to protect the threads from handling damage between the pipe racks and rig floor. Several thread protectors should be cleaned and used for this purpose. Use 'quickie' protectors if they will work.

5. Assemble the float shoe, shoe joint and float collar, applying thread-lock to the thread ends of the first 3 joints.

6. Make up and run the casing using the optimum torque values. Apply thread compound over entire surface of threads before stabbing. Use a fill up casing tool when running this casing.

\section{7" Intermediate Casing Cementing}

1. Cement the casing as follows:

(a) Install plug loading cement head, use a bottom and top plug. Pump 20 bbls. of mud flush spacer. Pressure test treating lines to 2000 psi.

(b) Mix and pump Halliburton HI Temp cement with 0.75\% Halad 322, 0.2\% HR-5, 0.2\% Super CBL mixed with fresh water to $15.8 \mathrm{ppg}$. Mix and pump at 5-6 BPM.

(c) Release the top plug and displace cement with water at a minimum of 6 BPM.

(d) Bump the plug to 500 psi over the pumping pressure. Release the pressure and check for flow back. If the float does not hold, shut-in and hold back pressure for four hours. Release the pressure in increments to avoid creating a micro-annulus. If the plug does not bump on the calculated volume, do not displace over $2 / 3$ the volume of the shoe joint.

PREPARED BY:

APPROVED BY:
DATE:

DATE: 


\section{LOGGING PROGRAM}

\section{CONTACTS}

\section{SERVICE COMPANY CONTACTS:}

\begin{tabular}{|c|c|c|}
\hline SERVICES & CONTRACTOR & TELEPHONE \\
\hline SURVEY & Blake Surveying & \\
\hline LEASE CONST. & General Production (Tom Burke) & 661-203-3736 \\
\hline CONDUCTOR & General Production (Rusty) & $661-765-5330$ \\
\hline DRLG. RIG & Nabors \#473 & $661-322-4983$ \\
\hline CASING ACC./Cent. & Gemoco & $661-391-9022$ \\
\hline 10 3/4" Casing & J.D. Rush & $661-392-1900$ \\
\hline 7" Casing & J.D. Rush & $661-392-1900$ \\
\hline UBD Service & Weatherford- Gary Colvin & 661-746-0887 \\
\hline DRLG. MUD & Geo Drilling Fluids & $661-325-5919$ \\
\hline CEMENTING & 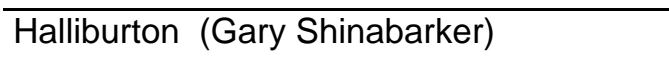 & $661-393-8111$ \\
\hline LOGGING & Horizon & $805-736-2114$ \\
\hline WELLHEAD & United (Bob Allen) Shreveport, LA & $318-424-4700$ \\
\hline ELECTRIC LOGGING & Halliburton (Lanny Jones) & $661-831-1374$ \\
\hline TRAILER（） & $\overline{B L L}$ & $661-589-9080$ \\
\hline PVT/ELECTONIC & W/rig Epoch & 661-328-1595 \\
\hline TRASH TRAILER & & \\
\hline SUPERVISION & Imke Consulting, Inc.Lloyd Rosenbaum & $661-619-1596$ \\
\hline Water & & \\
\hline DIRECTIONAL EQUIP. & Scientific Drilling & $661-831-0636$ \\
\hline Solids Equipment & Brandt & $661-588-8503$ \\
\hline WATER- Vac TRUCK & Speed's & $805-925-1396$ \\
\hline LAYDOWN & B\&L Casing & $661-589-9080$ \\
\hline SHOCK SUB/JARS & $\overline{\text { Black Max }}$ & $661-327-0226$ \\
\hline STABS & Downhole Stabilization & $661-631-1044$ \\
\hline POWER TONGS & B\&L Casing & $661-589-9080$ \\
\hline Tanks/water line & Tanks-speed's- water lines - Rain for rent & \\
\hline D.O.G.G.R. & $\begin{array}{l}\text { Division of Oil, Gas and Geothermal Res. } \\
\text { Ed Brannon Fax }\end{array}$ & $\frac{805-937-7246}{805-937-0673}$ \\
\hline Casing Hanger & Weatherford-Larry Peabody & $\underline{661-589-6743}$ \\
\hline BOPE Testing & $\underline{B L L}$ & $\underline{661-589-9080}$ \\
\hline Auto Driller & Wild Cat (Phil Morse) & $661-330-0317$ \\
\hline Welding & Tom Burke (General Production) & $\underline{661-203-3736}$ \\
\hline
\end{tabular}




\begin{tabular}{|l|l|}
\hline \begin{tabular}{l|} 
Choke equipment \\
Gas buster/Flair/Tanks
\end{tabular} & $\frac{\text { Swac0 }}{\text { Pacific Process Systems }}$ \\
\hline & $\underline{\text { Black Max- Mike Merriett }}$ \\
\hline
\end{tabular}

661-587-7787

661-589-8844

$661-327-0226$

\section{COMPANY CONTACTS:}

Temblor Petroleum LLC 2000 Oak St.

Office Fax: $661-395-5730$

Bakersfield, CA. 93389

Harold Imke

\begin{tabular}{|l|l|l|l|}
\hline SUPERINTENDENT: & HOME & HOME FAX & CELLULAR \\
\hline Harold Imke* & $661-397-6846$ & $661-397-6846$ & $661-809-2350$ \\
\hline & & & \\
\hline GEOLOGY & & & \\
\hline & & & \\
\hline & & & \\
\hline & & & \\
\hline
\end{tabular}

* - Primary drilling contact

Office: $\quad 661-397-6846$ 


\section{Appendix C}

\section{Daily Drilling Diary and Operational Comments}

The following summarizes daily drilling operations in well sections from surface hole to final TD.

The surface hole was drilled to 3561 ' in six days. Bit \#1 was a 143/4-in. Baker Hughes tricone bit Type GTX C1. While drilling the surface section, $50 \mathrm{bbl}$ of mud were lost at 224'. This is not an uncommon occurrence in the general area and was successfully treated with standard LCM (lost circulation material) placement. Final mud properties were a weight of $9.3 \mathrm{ppg}$ and a marsh funnel viscosity of 52 seconds. The well was successfully cased at 3555' MD with 103/4", 45.5\#/ft N80 BTC surface casing, cemented and pressure tested on Sept. 20, 2004 (Day 9).

\section{Special Surface Casing Design}

The larger-than-normal surface casing had a burst pressure of 5200 psi and was designed to contain full estimated reservoir pressure. This casing was the outer string of the concentric slave string MPD/underbalanced system. The gas injection holes in the inner slave string of 7" tie-back liner could allow the surface casing to be exposed to the well pressure if the Drilling Deployment Valve ${ }^{\mathrm{TM}}$ failed. It likewise would have been exposed to high pressure when the drilling annulus (7" casing $\times 3 \frac{1}{2}$ " drill pipe) was pressured to open the DDV.

\section{Drill 97/8" Intermediate hole and upper curve into top of the Monterey Formation}

The first part of this task was to drill a $97 / 8$ " vertical intermediate hole to a kick-off point (KOP) of 9143'. This vertical section was drilled using directional tools to keep the hole straight in the steeply dipping beds of the Miocene Sisquoc formation.

\section{Interval 3561' to 5006'}

A total of 1445 ' was drilled in 54 drilling and circulating hours, at a total time of $4 \frac{1}{2}$ days. Bit \#2 was HTC MX-C1 tricone (IADC code 117) fitted with 1 X14, 3 x 16 jets. Directional assembly No. 1 employed a $73 / 4^{\prime \prime}$ motor with a $1 \frac{1}{2}{ }^{\circ}$ bent sub. Drilling rate was about $30 \mathrm{ft} / \mathrm{hr}$ in both rotating and steering modes. Approximately $3 \%$ of the footage was drilled in the steering mode to maintain vertical angle and the remainder was drilled in rotary mode. The water-based mud density was gradually increased to $10.8 \mathrm{ppg}$ and funnel viscosity to $48 \mathrm{sec}$. The bit was pulled when penetration rate slowed. The bit showed wear on the outer row of teeth. 


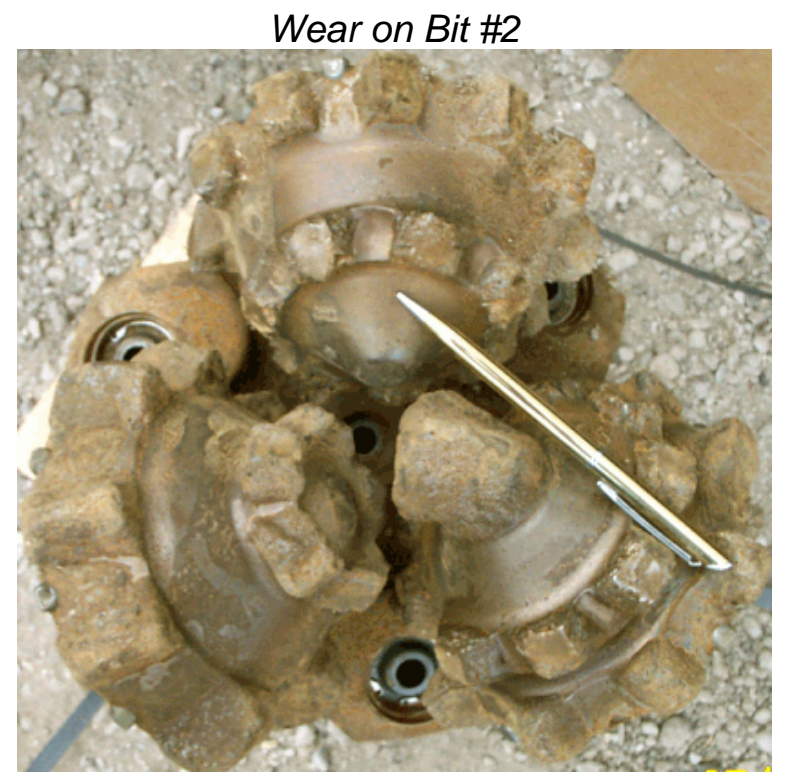

\section{Interval 5006' to 6054'}

A total of 1048 ' of vertical hole was constructed in 56 drilling and circulating hours, at a total time of 3 days. Bit \#3 was an HTC MX-1 tricone (IADC Code 117) fitted with 1x12, 2x15 jets. Directional assembly No 2 employed a $73 / 4^{\prime}$ motor with a $1 \frac{1}{2}{ }^{\circ}$ bend sub. Drilling rate was about $20 \mathrm{ft} / \mathrm{hr}$ in both rotating and steering modes, with 5\% of the footage being steering and $95 \%$ rotated. Mud density was gradually increased to $10.9 \mathrm{ppg}$ and funnel viscosity to 49 sec/qt. The bit was pulled when drilling rate decreased after 56 hours. The bit showed wear on the inner row of teeth. Mud logging samples indicated the top of the Sisquoc was penetrated at around 5725' MD.

\section{Interval 6054' to 9143'}

A total of 3089' of vertical hole was constructed in 119 drilling and circulating hours, at a total time of 5 days. Bit \#4 was a Security PDC, HC805, Jets $5 \times 12,2 \times 15$. The directional assembly No 3 employed a $73 / 4^{\prime \prime}$ motor with a $1 \frac{1}{2}{ }^{\circ}$ bent sub. The drilling rate achieved was $34 \mathrm{ft} / \mathrm{hr}$ while rotating and $10 \mathrm{ft} / \mathrm{hr}$ while steering. Around $10 \%$ of the footage was drilled in the steering mode.

The previous conventional tricone bit runs were unsatisfactory in the vertical hole section from both a drilling rate and footage standpoint. The first of the special efforts to improve the drilling came with the use of Bit No.4, a PDC bit. The bit would drill up to $100 \mathrm{ft} / \mathrm{hr}$ when rotating, but it unfortunately was a straight hole bit design with a long shank and would hang up on the side of the hole when sliding. This reduced the effective rate of penetration in the steering mode by an order of magnitude to $10-15 \mathrm{ft} / \mathrm{hr}$.

There were minor hole problems observed in this interval with the Sisquoc Formation. It is known as a pressured shale. In this case the shale appeared to be stressed as a result of the Central California Coast that is undergoing geological movement. There may also be some geo-pressure due to excessive fluid in the shale. There were very large cavings observed and some "reaming to bottom on trips" was required. This condition gradually improved as the mud density was increased from $10.6 \mathrm{ppg}$ to $11.4 \mathrm{ppg}$, but never completely disappeared. 


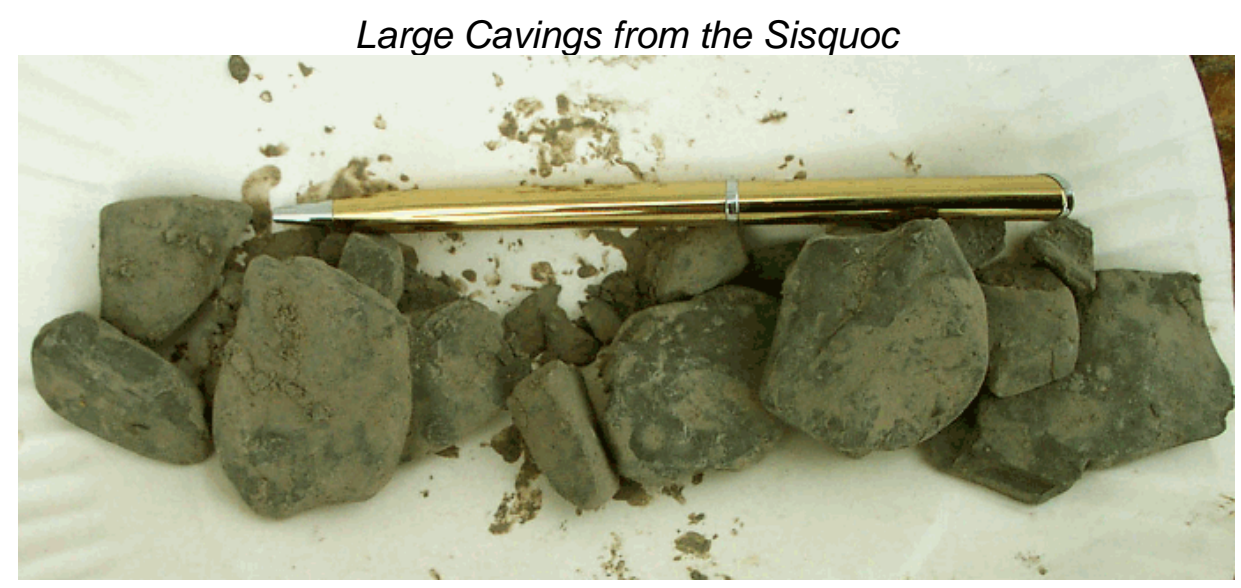

\section{Interval 9143' to 9705' (Upper Curve)}

The upper curve drilling plan called for a build rate of $61^{\circ} / 100^{\prime}$ at $298^{\circ}$ Azimuth. A total of $562^{\prime}$ of upper curve was drilled from $1^{\circ}$ to $23.5^{\circ}$ hole angle in 72.75 drilling and circulating hours, at a total time of 4 days. Bit \#5 was a HTC MX S18 tricone (IADC code 447) (insert cutters) fitted with $3 \times 20$ jets. Directional assembly No. 4 employed a $6 \frac{1}{2}$ " motor with $1 \frac{1}{2}{ }^{\circ}$ bent housing. Drilling rate was $91 / 2 \mathrm{ft} / \mathrm{hr}$ with $35 \mathrm{kips}$ on bit while rotating and $73 / 4 \mathrm{ft} / \mathrm{hr}$ with 35 to $50 \mathrm{kips}$ on bit when steering. The bit was rotated $299 \mathrm{ft}$ and steered $263 \mathrm{ft}$ for $53 \%$ rotating and $47 \%$ steering footage. The drilling rate was disappointing with this insert cutter bit, which was pulled for slow penetration rate. It was missing an insert, but otherwise showed very little wear.

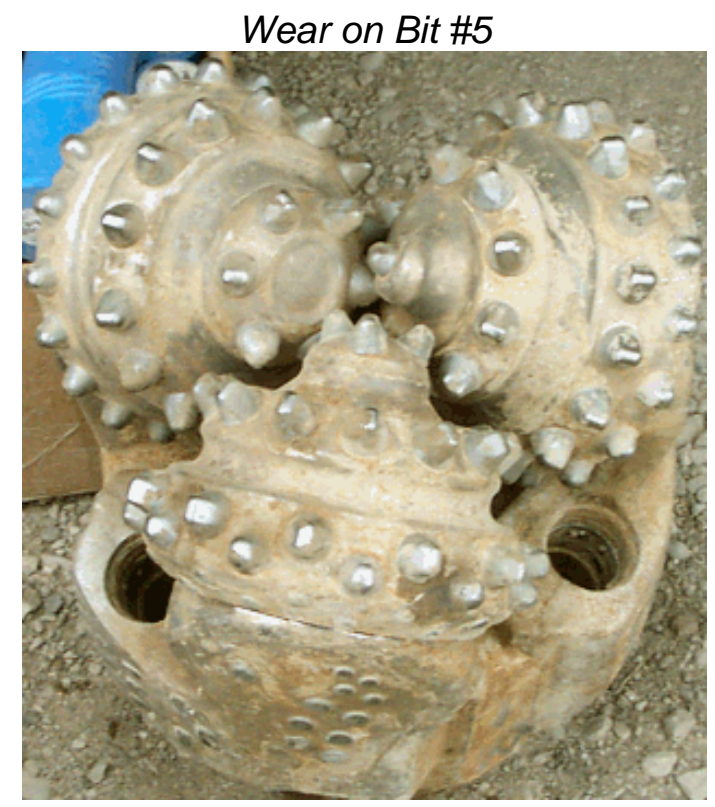

Mud density was raised from $11.2 \mathrm{ppg}$ to $11.7 \mathrm{ppg}$ in this upper curve interval and a $47 \mathrm{sec} / \mathrm{qt}$ funnel viscosity maintained. Mud logging samples showed variability that indicated the top of the Monterey shale sequence had been penetrated near 9619'. It was necessary to ream back into hole from 8284 ' to 8450 ' with the new directional assembly.

At a depth of $9161^{\prime}$ the operator insisted the build rate be reduced to $3^{\circ} / 100 \mathrm{ft}$, since he was unsure of the top of Monterey shale section. A short wiper trip was conducted at 9470' and 
bridges were observed at 9370-9390'. At a depth of 9705', another wiper trip to surface casing observed tight hole at 9470-9707'. At a depth of 9619' build rate was increased since it appeared the hole was nearing the top of the Monterey target.

\section{Interval 9705' to 9788'}

A total of $83^{\prime}$ of upper curve was drilled from $23.5^{\circ}$ to $28.14^{\circ}$ hole angle in 22.75 drilling and circulating hours, at a total time of 2 days. Bit \#6 was a MX C-1 tricone rock bit (IADC Code 117 ) fitted with $3 \times 20,1 \times 18$ jets. Directional assembly No.5 employed a $6 \frac{1}{2}$ " motor with $1 \frac{1}{2}{ }^{\circ}$ bent housing. Drilling rate was $4.8 \mathrm{ft} / \mathrm{hr}$ rotating with $45 \mathrm{kips}$ on bit and $4.8 \mathrm{ft} / \mathrm{hr}$ steering with $55 \mathrm{~K}$. The bit was rotated 24 ' and steered 59 ' for $71 \%$ steering footage.

Drilling rate was also disappointing with this tricone bit, and the bit was pulled for slow penetration rate. Minor tooth wear was observed. Mud density was maintained at $11.7 \mathrm{ppg}$ in this interval with a $46 \mathrm{sec} / \mathrm{qt}$ funnel viscosity. Mud logging samples still showed the transition from the lower Sisquoc to the upper Monterey. There was concern expressed about the length of time (approximately 14 days at this point) the Sisquoc had been exposed as open hole. The drill pipe showed a black film of iron sulfide with a mud $\mathrm{pH}$ in the 7 to 7.5 range. A trip to repair the top drive was conducted at a depth of 9782' and 35' of fill was observed on bottom. At a depth of 9788' a wiper trip was conducted in preparation to trip for a new bit. This wiper trip required reaming of a tight-hole interval, 9630'-9567', with $25^{\prime}$ of fill observed when going back to the bottom of the hole. Then a round trip was conducted for bit \#7.

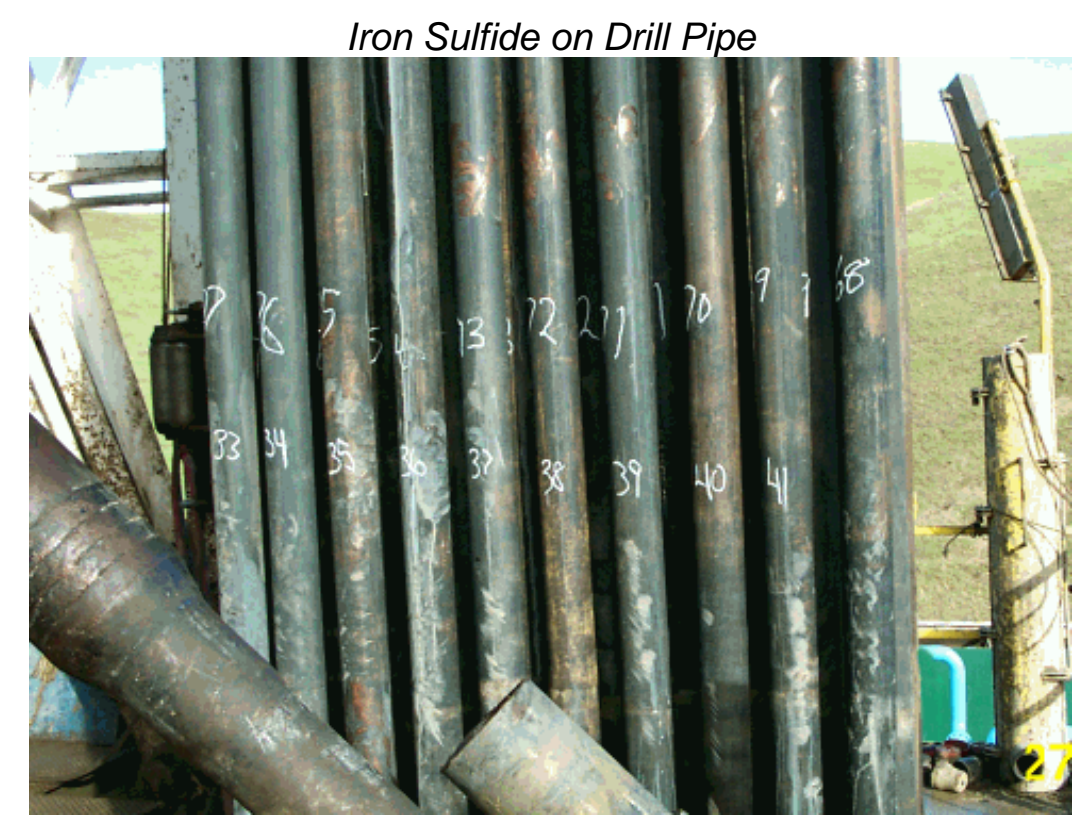

\section{Interval $9788^{\prime}$ to $10,261^{\prime}$}

A total of $473^{\prime}$ of upper curve was drilled from $28.14^{\circ}$ to $58.48^{\circ}$ hole angle in 38.75 rotating and circulating hours, at a total time of 2 days. Bit No 7 was a Security PDC, MGR75KP, fitted with $5 \times 18$ jets. Directional assembly No. 6 employed a $6 \frac{1}{2}$ " motor with $1 \frac{1}{2}{ }^{\circ}$ bent housing. Drilling rate was $10.5 \mathrm{ft} / \mathrm{hr}$ when rotating with 2-10 kips on bit and $14.5 \mathrm{ft} / \mathrm{hr}$ when steering with 5-30 kips bit weight. The bit was rotated 72 ' and steered 401 ' for $85 \%$ steering footage. Penetration rate was slightly better than tricone bits used previously, and gradually increased as the formation became more brittle. The dominant steering time employed in this interval was to increase 
angle. This bit was pulled to run the 7 " liner. The bit showed some matrix wear on the bottom, with one pocket partly exposed. There was no visible cutting wear.

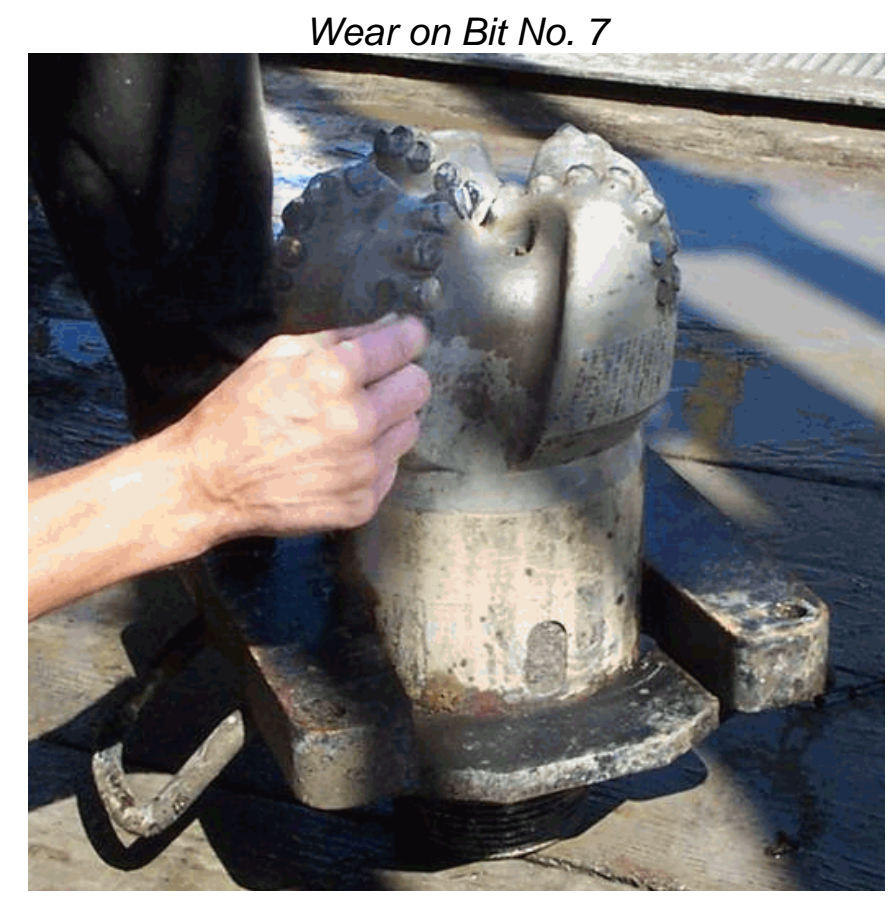

The mud logging samples showed that the upper curve had penetrated the top of Monterey target zone at almost exactly the estimated TVD of 10,000'. Samples showed increased siliceous shale. At 10,235-10,240' MD, a major fracture with gas, oil stains, and calcite was encountered. At 10,258' after the daily short trip to wipe the hole, it was decided to line the hole at this point to avoid putting a potentially productive fracture behind the 7" liner. The last wiper trip had indicated only $5^{\prime}$ of fill on bottom at 9788'. At a depth of 10,195', a short wiper trip to 9650 ' was conducted with no hole problems observed.

The drilling assembly was then pulled and the hole was reamed with a $95 / 8$ " bull-nose reamer assembly on 5" drill pipe. A bridge was noted at 10,145' going in hole. The well was circulated and the assembly pulled with minor indications of tight hole at 10,131-9956'.

Conventional tricone tooth and insert bits were unsatisfactory in this interval from both a drilling rate and footage basis. Improvement came with the use of directional PDC bits. Drilling rate was only slightly better than with tricone bits, but the PDC drilled 473' and showed only some matrix wear. There was fill-up of very large cavings, apparently from the exposed Sisquoc shale section observed during bottoms-up on circulations. The 11.7-ppg mud density reduced some of the caving, but it appeared that caving was still occurring in the freshly drilled part of the hole. There was a thin coat of iron sulfide on the drill pipe, possible as the result of a 7-7.5 $\mathrm{pH}$ mud condition.

\section{Installing Intermediate 7" Liner at 10,216'}

On Day 32, 6900' of 7" intermediate liner was run to $10,216^{\prime}$ on $5^{\prime \prime}$ drill-pipe and hung at 3279' MD in the surface casing. When the liner was being run, between 10,131-10,216' it began to stick and became difficult to reciprocate. At 10,216' the liner was stuck on bottom and could not be reciprocated. The rig circulated for about 50 minutes with $90-95 \%$ returns. Apparently, when 
cavings from the bottom of the well reached the liner hanger assembly at 3270', the well packed off, pump pressure spiked from 500 to 1400 psi, and returns were lost.

It appears that the rapid and unexpected spike in circulating pressure set the hanger slips. Further circulation was not possible. Several hours later, the hanger packer was set. The casing was not cemented at this time. Three days later on day 35, the casing lap was tested. Then the 7" liner was successfully squeezed cemented through the liner shoe with $286 \mathrm{ft}^{3}$ of cement that filled the annulus from 10,216-9,200'. The cement top behind the liner was observed where expected on a temperature log.

The tie-back 7" slave string was then run and landed at 3285.46'. It could not be pressuretested due to a stack-out calculation error. It was reset at $3306.22^{\prime}$ and then passed the pressure test.

\section{Productive Interval 10,258 ' to $12,789 '$}

\section{Rigging Up for MPD Operations}

A packer was run in, set in the 7" hanger, and successfully pressure tested the seal on the 7" tie-back string/liner hanger assembly. This packer was then pulled and laid down. The 61/8" drilling assembly was picked up and directional tools checked. The assembly was RIH to top of cement at 10,004' where cement was cleaned out to the 7" liner shoe. The shoe track was drilled out and a successful PIT was conducted.

To begin MPD, the concentric annulus was displaced with air and at a maximum pressure of 1400 psi to unload the drill pipe annulus. The surface choke on the underbalanced-drilling manifold was inadequate and would not properly operate. This choke had an air balance operating system that was unstable at the volumes and pressures encountered. The choke was bypassed and a plug valve in the "straight through-line" (of the manifold) was successfully used as a fixed choke for all further drilling.

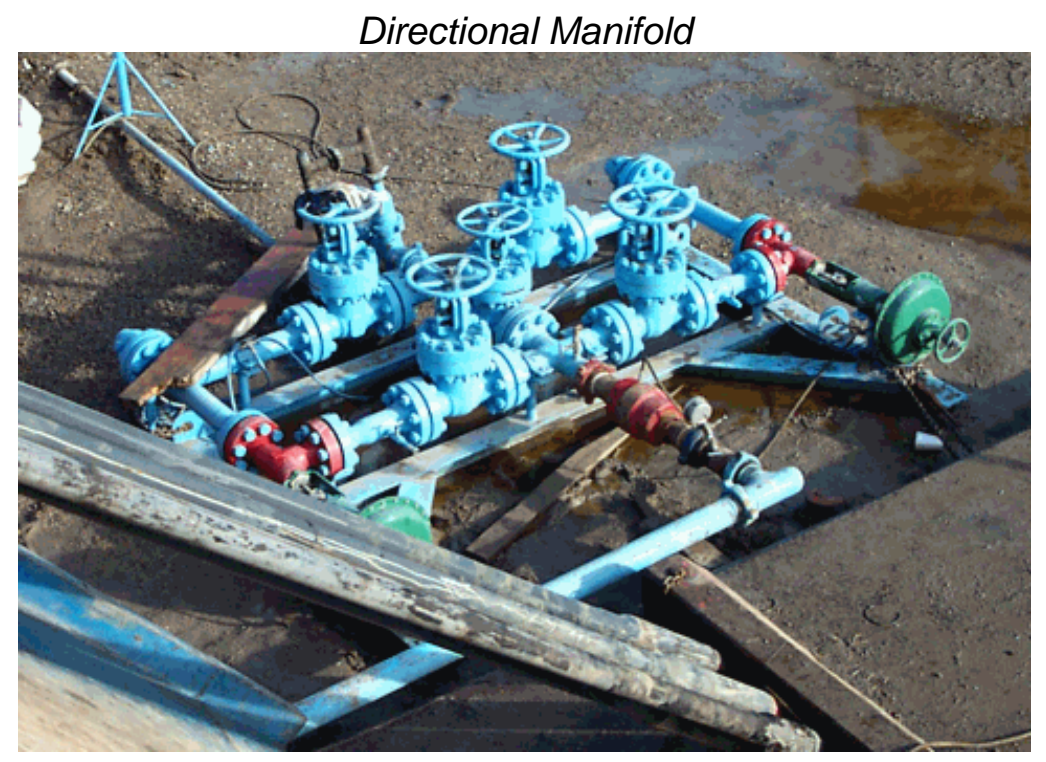




\section{Interval 10,258 ' to $11,319^{\prime}$}

A total of 1061 ' of $61 / 8$ " open hole tangent and lower curve was drilled in 3 days using the MPD slave string air-lift method described. The hole was drilled from 10,258' MD at $64^{\circ}\left(10,073^{\prime}\right.$ TVD) to 11,319' MD (10,363' TVD). The interval was drilled with a single PDC bit in 64.5 rotating hours at an average rate of penetration of $14.5 \mathrm{ft} / \mathrm{hr}$. At the start of this interval, an unplanned tangent section was drilled in the rotary mode from $10,323-10,642^{\prime}$ at $62-63^{\circ}$ angle to lower the position in the Monterey section.

The penetration rate reflects $632 \mathrm{ft}$ of tangent drilled rotating and then $429 \mathrm{ft}$ drilled sliding to complete the lower curve build section to the target $\pm 80^{\circ}$ hole angle. The assembly was then tripped out of the hole to check the bit, motor, and hole condition. PDC bit \#8 was in good condition and was rerun; however, the worn drilling motor was changed. There was no unusual drag on the hole and minimal cavings were observed on circulating bottoms up after the trip.

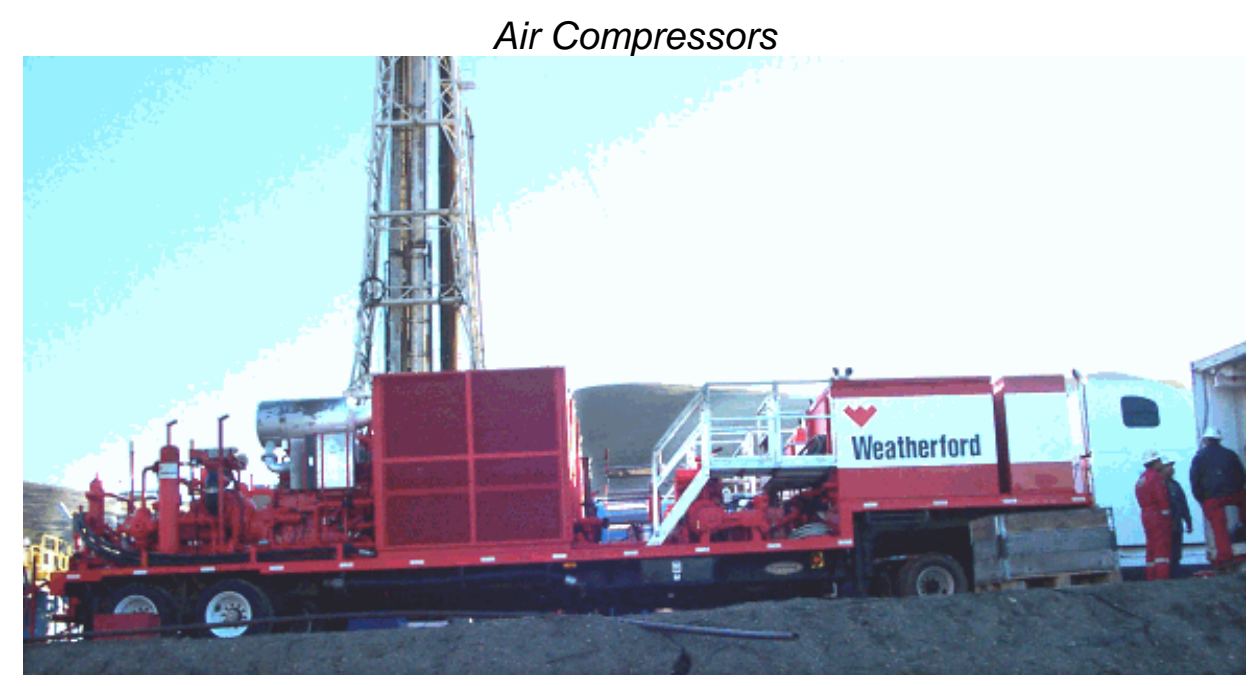

\section{Comment on initial MPD Operations}

There was a problem originally with surging the hole due to the large concentric annulus (103/4" x 7"). The compressor pressure surged from 8000 psi to 1400 psi on a 50-60 min. cycle. Bottom-hole pressure changed from 4000 psi to an estimated 4400 psi in the same intervals. Air volume was generally 700 to $1200 \mathrm{cfm}$ in the period and there was minimal choke pressure. In the drilling plan, the MPD provider had intended to use a larger air volume with a 150 psi back pressure to control surging. This was not done at the start, and after representation to the service provider, the original plan was re-instituted by a replacement service company supervisor.

At 11,000' MD, air volume was increased to $1833 \mathrm{cfm}$ with 200-psi back pressure on the choke. Surging stopped at 900 psi compressor pressure and 200-psi choke pressure. Bottom-hole pressure stabilized at about 4200 psi. On subsequent trips, circulating bottoms up indicated that there was no sign of caving or sloughing in the hole due to the cycling of the pressure in early MPD operations. 


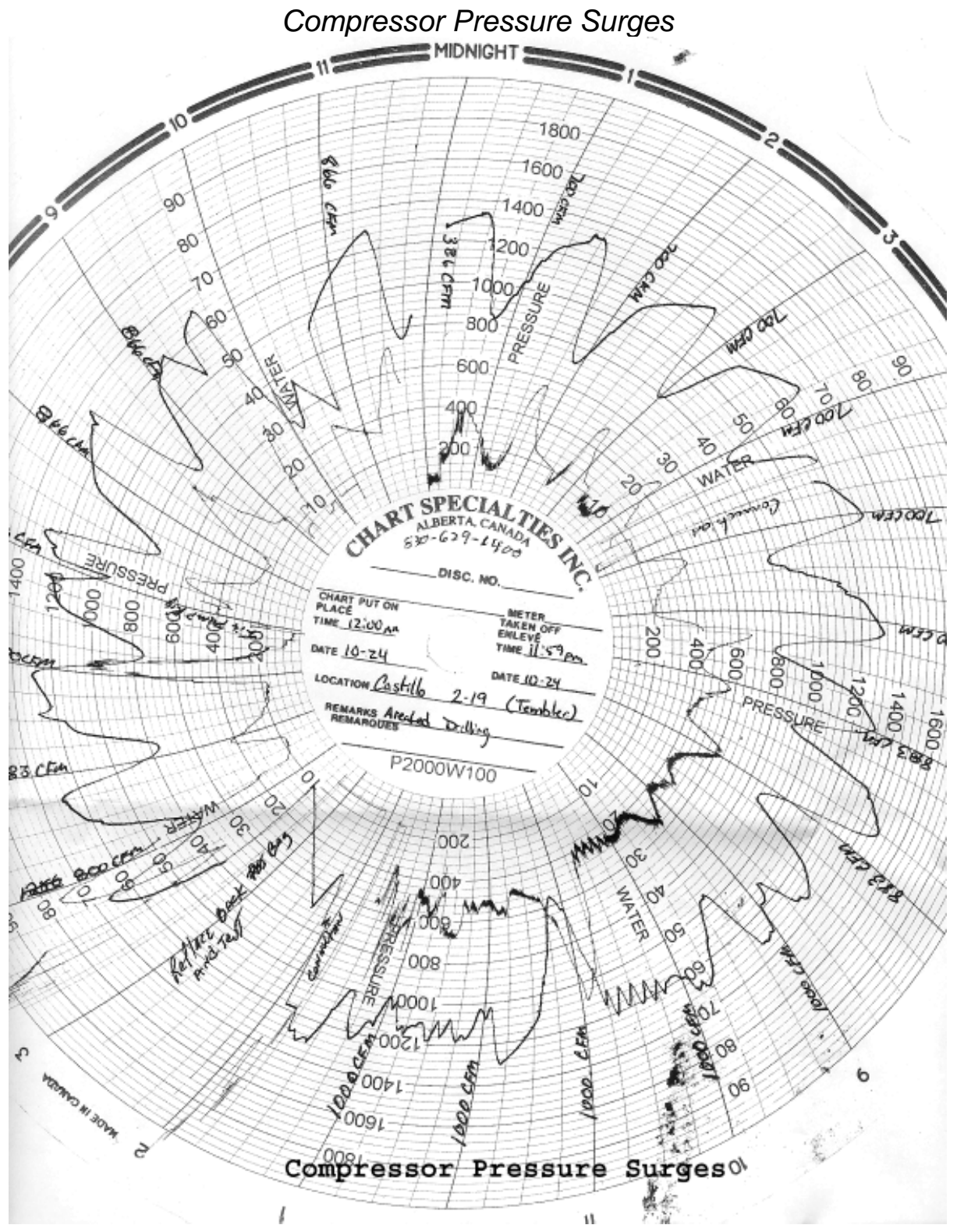




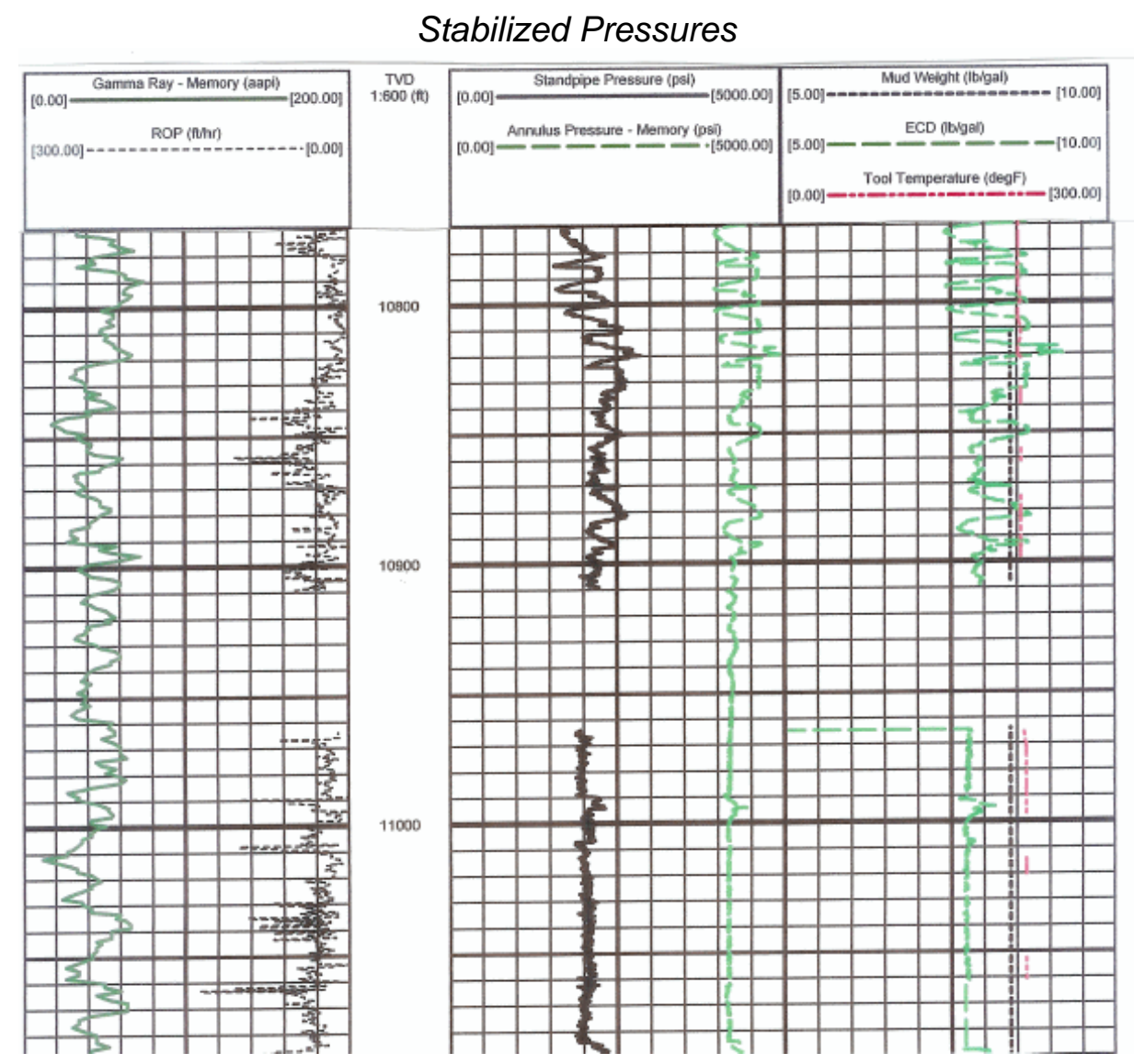

The Drilling Deployment Valve was never used since there was no major gas or oil flow or reservoir pressure. On all trips the hole was filled with water before tripping. After all trips, the water column was circulated bottoms up before air injection was resumed.

In the original well design, the bottom of the Monterey fractured interval was expected to occur near 10,350' TVD. When drilling at 10,327' TVD the gas detector showed a marked decrease in gas. The gas appeared to resume at a horizontal distance of $312 \mathrm{ft}$ at a TVD of 10,362'. At a measured depth of 11,153' a marked change in drilling characteristics was observed, and the driller noted that the bit was easier to control in this interval. It appears that the well may have drilled out of the bottom of the Monterey highly fractured target at this point, and then returned into the section (from approximately 11,300-11,900' MD). This could be either a fault (no evidence of that) or that the Monterey dips around $6.4^{\circ}$ to the northwest. Good micro-fracturing and oil and gas shows did not appear again until 11,900' MD (about 10,460' TVD). This interpretation of well placement is consistent with the seismic prognosis indicating that the target Monterey shale was dipping to the northwest along the well path.

The change from surging the hole about $90 \mathrm{bbl}$ to a steady-state flow changed the mud logger's gas readings in the interval where the well path might have dropped out of section. So the collaborating evidence is not altogether clear with respect to how much of the mid length was below the highly fractured shale member. 


\section{Interval $11,319^{\prime}$ to $12,789^{\prime}$}

Continued drilling of the 61/8" "horizontal hole" was delayed another two days by rig repairs. While waiting, a gamma ray sensor was added to the MWD. From day 53 through day 66, the well was drilled 1470 ' to TD in 13 days. There were 147.5 hours $(47 \%)$ of the total 312 hours listed as drilling or rotating hours which included surveys and connections. The average drilling rate was about $10 \mathrm{ft} / \mathrm{hr}$. Of the $1470 \mathrm{ft}$ drilled, 1234' were rotated and the remaining 173' were corrective directional sliding. The bottom-hole temperature was measured as $230-260^{\circ} \mathrm{F}$. During this period of 13 days, there were eight trips to change bits, motors, or survey equipment. Some trips showed multiple failures:

\begin{tabular}{|l|l|}
\hline Mud motor & 5 failures \\
\hline MWD or survey electronics & 2 failures \\
\hline Bit failure or wear & 4 failures \\
\hline
\end{tabular}

On Day 53, rig repairs were finished and PDC bit \#8 was rerun with a gamma ray MWD sensor. This bit drilled from 11,319-11,382' in 3.5 hours.

Day 54 was spent drilling from 11,382-11,516' (7 hr). A trip was then conducted for failure in directional electronics in MWD. When back on bottom, traces of oil $(<1 \mathrm{bbl})$ were observed, as well as increased gas in bottoms-up.

Day 55 was spent drilling from 11,516-11,804' (351/2 hr). Drilling rate was decreasing, and the assembly was then pulled for failure of the mud motor bearing pack (sealed bearings lost seal). The gamma-ray log showed a single peak at 11,690'. At survey depth of 11,700' MD (10,426' TVD), well inclination was $81^{\circ}$ on an azimuth of $299^{\circ}$. There were no clear drilling breaks observed in this interval.

After tripping in with a new motor, Day 56 was spent drilling from 11,804-11,849'. Again, the mud motor bearings froze up (sealed bearing motor). Only traces of oil and gas were observed in the bottoms up circulation prior to tripping out of the well to replace the motor.

Day 57 was spent tripping for the new motor, and drilling from 11,849-11,890' MD. After drilling $41^{\prime}$ and 3.5 hours, the mud motor failed again. The bottom-hole temperature from MWD readings at the time of failure was $248^{\circ} \mathrm{F}$ after $4.5 \mathrm{hrs}$ of circulating. Another trip was required to replace the motor.

After getting back to bottom and washing bridges at 11,014' and 11,563' (first bridges noted in hole since setting the 7" liner was set), Day 58 was spent drilling to 12,074'. No significant gas or oil was observed in the bottoms up circulation. Penetration rates of 4-6 ft/hr were gained in the sliding/rocking mode with 60 kips stacked over the bit. Drilling rate while rotating was 15-25 $\mathrm{ft} / \mathrm{hr}$ with $14 \mathrm{kips}$ on bit. Bottom-hole pressure was maintained near 4400-4500 psi. The gamma ray log (below) started showing continuous peaks at around 11,900' MD, although there were no obvious drilling breaks, but a minor increase in bottom-hole temperature was observed. 


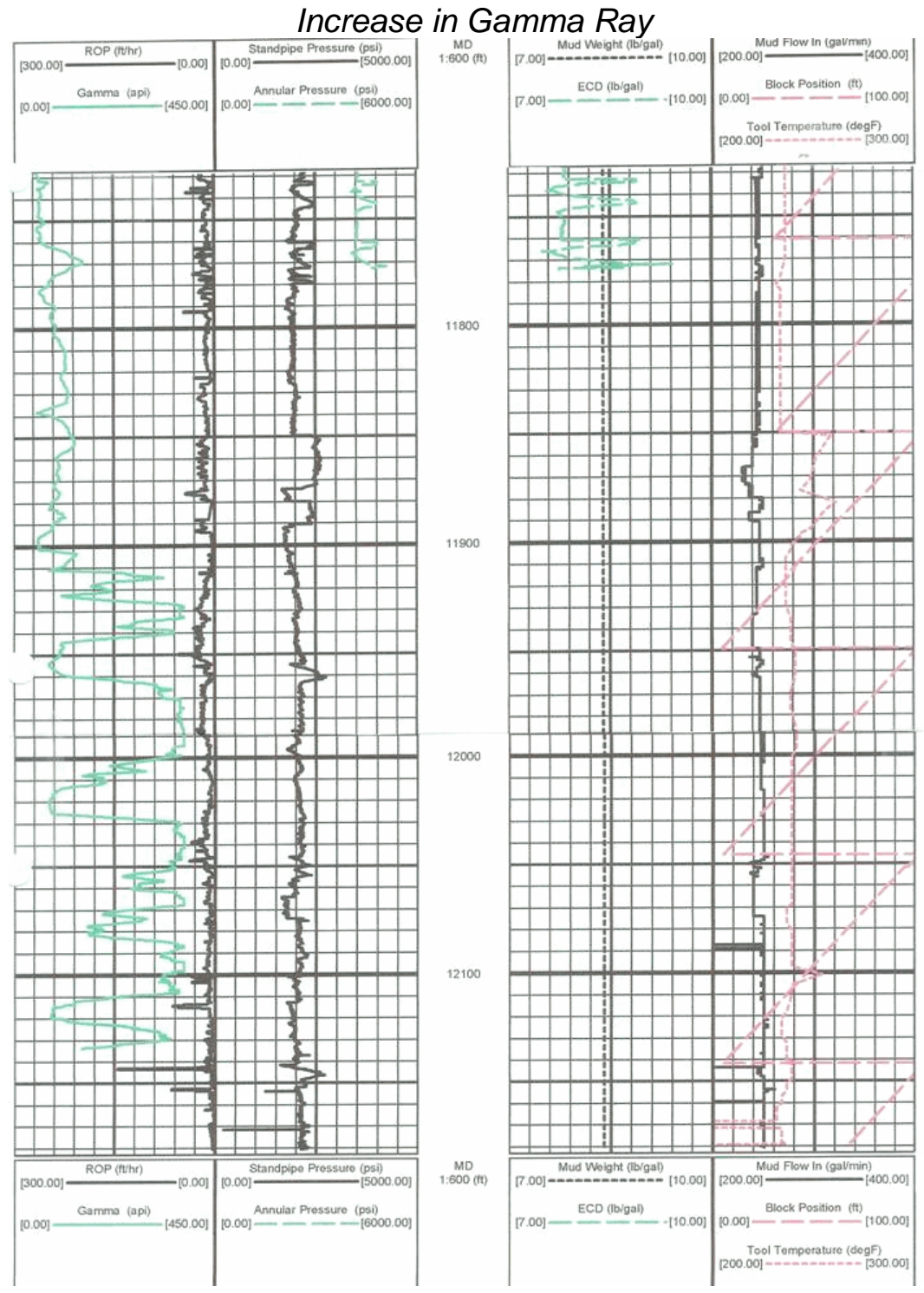

Day 59 was spent drilling in a combination of rotary and sliding/rocking mode from 12,07412,168 '. Drilling rate was very slow but there was increasing evidence of fractures with gas and oil observations at surface.

Day 60 was similarly spent drilling from 12,168-12,193' with very slow drilling. A trip was made to replace a suspect motor, and 55 gallons of high-temperature lubricant were added to the drillin fluid. Bottom-hole temperature after the trip was monitored at $258^{\circ} \mathrm{F}$; after $4 \mathrm{hr}$ of circulating it cooled to $238^{\circ} \mathrm{F}$. After being pulled, bit \#8 was $80 \%$ worn, showing a junk ring and showing possible $1 / 8$ " out of gage. And it was also noted that an Allen screw was missing from the MWD hang-off sub. 


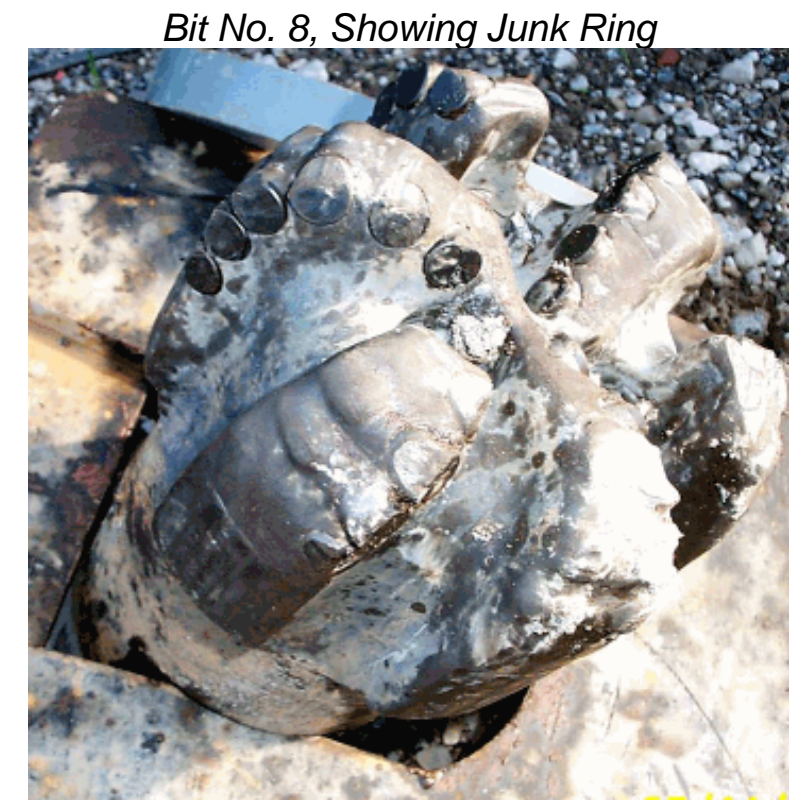

A new PDC bit (\#9) and sealed bearing motor were run on Day 61. A good gas flare was observed for 20 minutes on the bottoms-up circulation, and about $1 \mathrm{bbl}$ of oil was gained. The maximum recorded bottom-hole temperature of $258^{\circ}$ was observed at this time. Penetration rates were $30 \mathrm{ft} / \mathrm{hr}$ in the rotary mode, and 7-13 ft/hr in the slide/rock mode. After drilling 23', the motor failed (broken shaft) and a trip was conducted. At surface the PDC bit appeared damaged (ringed on bottom), perhaps caused by the missing MWD screw left in the hole.

In the next 4 days, three new insert tricone bits were runs (HTC MX20DX Nos. 10, 11, 12). Bit \#10 drilled 164' in 161/2 hours, at an average rate of $10 \mathrm{ft} / \mathrm{hr}$; bit \#11 drilled 189' in 16 hours, at an average rate of $11.8 \mathrm{ft} / \mathrm{hr}$; bit \#12 drilled 219' in 21 hours, at an average rate of $10.4 \mathrm{ft} / \mathrm{hr}$.

Day 62 was spent tripping in the hole with the new bit \#10 and motor assembly. The hole needed to be reamed from 11,188-11,283'. The well was drilled 139' rotating with one 23' slide. The bottoms-up circulation show gas and oil.

Day 63 was spent drilling $36^{\prime}$ and then tripping out of hole at $12,381^{\prime}$ for a MWD failure. At surface, bit \#10 (tricone) was graded as worn. The bit was replaced with bit \#11 and run in hole. The bottom-hole temperature was recorded at $238^{\circ} \mathrm{F}$.

Day 64 was spent drilling an additional 189' and then tripping out of hole at 12,537' for a bit change to bit \#12. There was a slight increase in bottom-hole temperature from $238^{\circ} \mathrm{F}$ to $250^{\circ} \mathrm{F}$, and some oil and gas was observed on bottoms-up circulation.

Day 65 was spent finishing the trip in the hole with bit \#12 and drilling 160'. The bottom-hole temperature was $250^{\circ} \mathrm{F}$ and a small increase in bottoms-up gas was observed. Finally, Day 66 was spent drilling to TD at 12,789' (survey depth). Drill breaks were observed at 12,727$12,730^{\prime}$. The final survey was at a measured depth of 12,789', TVD of 10,513', azimuth of $297^{\circ}$, and inclination of $88^{\circ}$. 


\section{Appendix D}

\section{Temblor Petroleum Castillo 2-19}

\section{Synopsis of Petroleum Indicators in the Monterey Formation}

The Castillo 2-19 well was drilled within abundant siliceous rocks which are potential reservoirs and hydrocarbon source rocks. Mud logging commenced from 3561'. Chromatography showed the expected presence of trace heavy gases within the Sisquoc Formation. Other oil indicators were present in trace amounts by 9550'. Oil shows increased in the Monterey Formation and are present continuously to Total Depth of 12,789'. Mud logged indicators suggest good potential for Monterey Formation oil production, however there is no prior history of underpressured Managed Pressure Drilling method in Monterey.

\section{Mechanics and Technology}

Down to 10,261 ' the well was mud logged in a conventional manner. Cuttings samples were recovered from the shaker screens. Gas was drawn from an agitator gas trap in the flow line.

From 10,261' to TD the well was drilled with managed pressure drilling (MPD) in an underpressured condition. Cuttings sampling was problematic with the apparatus used. Returns from the wellbore traveled through an entirely closed flow line into a large tank. Some experimentation was needed to determine the best source for solid samples. Usually but not always the best samples were recovered from a 3" dump valve on the bottom of the tank, closest to the flow line input. Quality of sampling was construed from these factors: apparent freshness, i.e., cuttings newly entering the tank; recovery of actual solids as opposed to fluid only; and the size and quantity (enough to examine) of solids.

Gas sampling was accomplished by connecting tubing into a $1 / 4$-inch valve on top of the tank. A vacuum was drawn on this tubing, as is customary in conventional mud logging drawing from a gas trap placed in the fluid stream returning from the wellbore. A pressure regulator at the valve prevented aberration from a continual, controlled gas sample stream. Consistency is essential for relative gas measurements.

Depth lagging was computed from fluid pumped, but the air input to create an underbalance was only averaged, thus making lagging less precise than usual. Nevertheless, as the well progressed the evidence of returning gas and samples suggested fairly accurate lagging, and variations implied that the cuttings were representative of the intervals drilled.

Samples were examined with a binocular microscope at 10 to 35 power. Gas was analyzed by a Shimadzu chromatograph equipped with dual Flame lonization Detectors. Chromatography was quantified by integration. Gas "units" are scaled at 200 ppm methane equivalence. It is worth noting that in some regions the local custom is to scale units at $100 \mathrm{ppm} \mathrm{CH}_{4}$; double the gas unit values reported here to relate them to gas readings in other regions. 


\section{Lithology and Hydrocarbon Shows}

\section{Above 10,261 ft}

The basal Sisquoc contains increasing laminated clay-rocks and biogenic rocks. Claystone, the dominant rock in Sisquoc, grades to shale with improved induration and fissility. By 9900' MD, shale is the dominant rock type. Dolostone beds also gradually increase in frequency and amount, usually present only as traces but occasionally up to $20 \%$. The Monterey shale is distinguished from Sisquoc by a slightly browner color tone and some flaggy cuttings habit in addition to the fissility and induration.

The first significant show and the first significant chert occurred at 10,195'. A significant fracture occurred at 10,237'. The clay rocks become virtually all shale, much of which is very siliceous and brittle, instead of claystone, with accompanying dolostone and argillaceous chert.

The fracture at 10,237' yielded 400 units of ditch gas, from a consistent background of 20 to 30 units, with a rich mixture of methane through pentanes. Live oil pops with moderate gold fluorescence accompanied the gas. The shale, chert, and dolostone are uniformly fluorescent. A trace of drusy calcite gave a fast streaming light yellow cut fluorescence. This is an extraordinarily good oil show for Monterey rocks drilled with 11.8+ ppg drilling mud. Clearly, a good fracture, possibly a fault, was encountered.

A general lack of oil stains on cuttings, and lack of heavy oil blebs, on the Monterey rocks in this well is not necessarily negative regarding the oil indicators. In fact, based on the other indicators and gas values the oil that may be moveable in the Monterey in this well is probably relatively higher gravity, and does not leave the heavier, more residual traces characteristic of many lower-gravity Monterey producers.

\section{$10,261^{\prime}$ to 10,820 ':}

Below 10,261' there was initial difficulty recovering a sufficient sample to examine due to drilling with a $61 / 8$ " PDC bit with a mud motor. Fast drill rates exacerbated the problem. The rocks may have been further pulverized by traveling under pressure through the long surface flow line with multiple elbows. The samples in the early part of the MPD were only marginally reliable - the solids were extremely small, making especially chert harder to detect. The log shows primarily siliceous shale with only minor amounts of chert and dolostone, never more than $10 \%$ chert and $20 \%$ dolostone. It is possible that chert and dolostone were more abundant, but less evident in the samples due to the very small size of pieces. The faster than usual drill rate would tend to suggest low content of chert and dolostone.

Oil shows and gas values were very good in the first part of the MPD section, though measurements were intermittent due to sporadic unloading of the wellbore. Fluorescent oil pops, light brown microscopic oil blebs in white light, and oil iridescence were noted. There is abundant cuttings sample fluorescence. Ditch gas was often several hundred units, and reached as high as 1500 units. These are excellent show indicators by the standards of normal Monterey sections drilled with mud. 


\section{$10,820^{\prime}$ to 11,940 ':}

Shows and gas decreased just below 10,820'. This is also the point where distinctive smectite tuff with bright mineral fluorescence becomes more prominent (traces occur at least as high as 10,370 '). Chert further decreased to traces only below 10,800', until occasionally reaching up to $10 \%$ below 11,430'. Dolostone persists in small quantities, and there is one interval from 11,275 ' to 11,300 ' where dolostone peaks at $40 \%$ of the sample. Small amounts of very fine sand and sandstone are present.

Ditch gas was low throughout this interval except for occasional episodic gas spikes when the amount of water relative to injected air fluctuated. Three bit trips in this interval resulted in 2900, 1300 , and 1000 units trip gas and a film of oily emulsion and free dark golden brown oil.

\section{1,940 ' to 12,789 ':}

Small amounts of chert occur beyond 11,420' and chert becomes common to abundant from 11,940 ' to T.D. Dolostone also becomes abundant in this section. Each of these rock types comprises up to $40 \%$ of the lithology, the remainder being hard brittle siliceous shale, and traces of sand. Oil shows increased again in this interval. Oil attributes include iridescence, fluorescent oil pops, and gold fluorescent background oil in the drill fluid. Samples display uniform dull gold fluorescence and weak to strong solvent cuts.

Ditch gas continued to be affected by sporadic air injection rates. Gas spikes were common, some of which did not appear to be related to air/water fluctuations. As before, the heavy gas components of pentanes and butanes were richly abundant.

Four trips occurred in this interval, with trip gas values of $3200,3500,2100$, and 1600 units. These are exceptionally high values for trip gas within the Monterey Formation. Oil slicks and oily film were seen after each trip. Following the trip at 12,193' dark brown to black free oil constituted up to $20 \%$ of the returning fluid.

This interval contains elements normally associated with good mud-log shows and oil producibility in the Monterey Formation: silicic and biogenic rocks; variation of rock types in close proximity; oil indicators such as sample fluorescence and solvent cuts on the rocks; oil indicators such as pops, visible free oil and iridescence on/in the drilling fluid; high ditch gas values; and favorable gas component proportions.

There are at least three notable fractures in the last 100' - at 12,689', 12,727', and 12,746'. These were marked by much faster drill rates, ditch gas increases that were not attributable to the air/water injection fluctuations, and gold fluorescent live oil pops. An oil slick formed on the fluid pits from returned fluid.

Chert and dolostone are much more abundant in this interval than in the previous sections. Drilling rates were substantially slower, too. This may be in part due to the extended lateral hole geometry or the use of insert bits rather than PDC bits, but the more obvious likely factor is the harder rock types as seen in the samples in this last interval. The evidence suggests that the most chert-rich, high resistivity part of the Monterey was not penetrated until this last interval. 


\section{Summary}

Castillo 2-19 contains biogenic-rich reservoir quality lithology, especially chert and including dolostone and brittle siliceous shale, in the intervals 10,195 ' to $10,820^{\prime}$ and 11,940 ' to 12,789 '. Oil shows were good. Gas shows were outstanding, though the effects of MPD on the gas values are not clear. The cumulative amount of fracturing in formation along the wellbore is not clear from mud-logged evidence. The best evidence for optimal reservoir quality lithology was not seen until the last several hundred feet of the well. 